\title{
Effects of supplementing rumen-protected niacin on fiber composition and metabolism of skeletal muscle in dairy cows during early lactation
}

\author{
J. O. Zeitz, ${ }^{* 1}$ A. Weber, ${ }^{*}$ E. Most, ${ }^{*}$ W. Windisch,† C. Bolduan,† J. Geyer,† F.-J. Romberg,§ C. Koch,§ \\ and K. Eder* \\ *Institute of Animal Nutrition and Nutritional Physiology, University of Giessen, Heinrich-Buff-Ring 26-32 (IFZ), 35392 Giessen, Germany \\ †Chair of Animal Nutrition, Technische Universität München, Liesel-Beckmann-Strasse 2, 85354 Freising, Germany \\ łInstitute of Pharmacology and Toxicology, University of Giessen, Schubertstraße 81 (BFS), 35392 Giessen, Germany \\ $\S E d u c a t i o n a l$ and Research Centre for Animal Husbandry, Hofgut Neumuehle, 67728 Muenchweiler an der Alsenz, Germany
}

\section{ABSTRACT}

Nicotinic acid (NA) has been shown to induce muscle fiber switching toward oxidative type I fibers and a muscle metabolic phenotype that favors fatty acid (FA) utilization in growing rats, pigs, and lambs. The hypothesis of the present study was that supplementation of NA in cows during the periparturient phase also induces muscle fiber switching from type II to type I fibers in skeletal muscle and increases the capacity of the muscle to use free FA, which may help to reduce nonesterified fatty acid (NEFA) flow to the liver, liver triglyceride (TG) accumulation, and ketogenesis. Thirty multiparous Holstein dairy cows were allocated to 2 groups and fed a total mixed ration without (control group) or with $\sim 55$ g of rumen-protected NA per cow per day (NA group) from $21 \mathrm{~d}$ before expected calving until 3 wk postpartum (p.p.). Blood samples were collected on $\mathrm{d}-21,-14,-7,7,14,21,35$, and 63 relative to parturition for analysis of TG, NEFA, and $\beta$-hydroxybutyrate. Muscle and liver biopsies were collected on d 7 and 21 for gene expression analysis and to determine muscle fiber composition in the musculus semitendinosus, semimembranosus, and longissimus lumborum by immunohistochemistry, and liver TG concentrations. Supplementation of NA did not affect the proportions of type I (oxidative) or the type II: type I ratio in the 3 muscles considered. A slight shift from glycolytic IIx fibers toward oxidative-glycolytic fast-twitch IIa fibers was found in the semitendinosus, and a tendency in the longissimus lumborum, but not in the semimembranosus. The transcript levels of the genes encoding the muscle fiber type isoforms and involved in FA uptake and oxidation, carnitine transport, tricarboxylic acid cycle, oxidative phosphorylation,

\footnotetext{
Received January 24, 2018.

Accepted May 13, 2018.

${ }^{1}$ Corresponding author: Johanna.O.Zeitz@ernaehrung.uni-giessen.
} de and glucose utilization were largely unaffected by NA supplementation in all 3 muscles. Supplementation of NA had no effect on plasma TG and NEFA concentrations, liver TG concentrations, and hepatic expression of genes involved in hepatic FA utilization and lipogenesis. However, it reduced plasma $\beta$-hydroxybutyrate concentrations in wk 2 and 3 p.p. by 18 and $26 \%$ and reduced hepatic gene expression of fibroblast growth factor 21, a stress hormone involved in the regulation of ketogenesis, by 74 and $56 \%$. In conclusion, a high dosage of rumen-protected NA reduced plasma $\beta$-hydroxybutyrate concentrations in cows during early lactation, but failed to cause an alteration in muscle fiber composition and muscle metabolic phenotype.

Key words: niacin, muscle fiber, lactating dairy cow, ketogenesis

\section{INTRODUCTION}

During the periparturient phase, high-yielding dairy cows are typically in a strong negative energy balance (NEB) as food intake capacity in this phase is limited and the amount of energy consumed does not meet the high requirement of maintenance and milk production. Negative energy balance leads to mobilization of nonesterified fatty acids (NEFA) from adipose tissue that are released into the blood. The major part of NEFA released from adipose tissue is taken up by the mammary gland and used for the synthesis of milk fat. Approximately $25 \%$ of the NEFA passing through hepatic circulation are taken up by the liver (White, 2015). Part of these NEFA is subjected to $\beta$-oxidation in the liver. However, as the capacity of $\beta$-oxidation in the liver is limited during the periparturient phase, a part of the NEFA is also incorporated into triglycerides (TG), which under physiological conditions are secreted into the blood via very low density lipoproteins (VLDL). However, as the capacity for synthesis and secretion of VLDL in the liver in dairy cows is also limited during this period, TG are accumulating in the liver. 
Consequently, liver TG concentrations increase after parturition, which can impair liver function and result in fatty liver development (Hocquette and Bauchart, 1999; White, 2015). The development of a fatty liver is of high clinical relevance in dairy cows because it not only impairs liver function but also increases the risk of other diseases such as ketosis (Bobe et al., 2004). It has been well established that concentrations of NEFA in plasma are directly linked with the development of fatty liver in dairy cows (Hocquette and Bauchart, 1999). Although NEFA are an important energy source in early lactation, an excessive NEFA supply to the liver will overburden its oxidative capacity, which is frequently found in early-lactating dairy cows (White, 2015). Therefore, nutritional strategies to counteract the development of a fatty liver in dairy cows should consider possibilities to lower plasma NEFA concentrations to a certain degree during the periparturient phase.

Nicotinic acid (NA) is a water-soluble vitamin that is involved in the metabolism of carbohydrates, fats, and proteins. However, NA in high dosages is also known to decrease concentrations of lipids, including TG and low-density lipoprotein, and to increase concentrations of high-density lipoprotein in the plasma of humans (Barter and Rye, 2016; Feingold and Grunfeld, 2017). It is known that NA, when binding to its receptor GPR109A, renamed hydroxy-carboxylic acid receptor 2 (HCAR2), inhibits adipose tissue lipolysis (Wise, 2003; Offermanns, 2006), which reduces the supply of NEFA for hepatic TG synthesis and hepatic VLDL assembly (Wang et al., 2001; Offermanns, 2006). A reduction in plasma NEFA concentrations has been confirmed in feed-restricted dairy cows when NA was infused postruminally, and the expected NEFA rebound occurred after NA infusion was terminated (Pires and Grummer, 2007). Although oral feeding of non-rumen-protected NA has yielded contradictory data concerning its effects on plasma NEFA concentrations, possibly because too low NA amounts were entering the bloodstream (Niehoff et al., 2009), feeding rumen-protected NA has been shown to reduce plasma NEFA concentrations in early-lactating dairy cows (Yuan et al., 2012). However, NA also has effects that are independent from activation of the HCAR2 receptor, such as, for example, its effect on plasma lipids (Feingold and Grunfeld, 2017). Therefore, the classic view that NA influences hepatic lipid metabolism mainly due to an inhibition of adipose tissue lipolysis has been put into question (Choi et al., 2011).

We have recently observed that high dosages of NA, resembling those required to achieve lipid lowering effects in humans, caused a shift from the glycolytic, fast-twitch type II fibers to oxidative slow-twitch type I fibers in various skeletal muscles of growing rats, pigs, and sheep (Khan et al., 2013a,b; Ringseis et al., 2013). In line with the fact that type I fibers are rich in mitochondria, exhibit high activities of oxidative enzymes, and mainly use fatty acids for energy production, the animals treated with NA showed an increased expression of genes involved in fatty acid uptake, mitochondrial fatty acid import, and oxidation and oxidative phosphorylation in skeletal muscles (Khan et al., 2013a,b; Ringseis et al., 2013). In parallel with the increased proportion of oxidative type I fibers, NA also induced an upregulation peroxisome proliferator-activated receptor $\delta$ (PPARD) and PPAR- $\gamma$ coactivator1- $\alpha$ (PPARGC1A), transcription factors that are key regulators of muscle fiber composition, mitochondrial biogenesis, fatty acid oxidation, oxidative phosphorylation, and angiogenesis (Wang et al., 2004; Schuler et al., 2006). This finding suggests that muscle fiber transition from type II to type I in animals treated with NA was caused by an induction of genes encoding critical regulators of muscle fiber composition, such as PPARD and PPARGC1A. In obese rats, NA treatment caused also a strong reduction of plasma NEFA concentration, associated with lower concentrations of TG in plasma and liver (Ringseis et al., 2013). It is likely that reduced plasma NEFA concentrations in the rats treated with NA were, at least in part, due to increased utilization of fatty acids in skeletal muscle, which significantly contributes to whole-body fatty acid utilization.

In the present study, we investigated the hypothesis that treatment of periparturient cows with high dosages of NA causes a muscle fiber switch in skeletal muscle similar to that observed in rats, pigs, and sheep (i.e., an increase of oxidative type I fibers at the expense of glycolytic type II fibers). Such an effect might be favorable in dairy cows as it is expected that an increase in type I fibers might enhance the uptake of NEFA released from adipose tissue into the skeletal muscle and the utilization of NEFA by $\beta$-oxidation. An increased uptake of NEFA into the skeletal muscle might lead to a reduction of plasma NEFA concentration and in turn to a reduced uptake of NEFA into the liver causing a decrease in TG accumulation and ketogenesis.

\section{MATERIALS AND METHODS}

The study was carried out at the Educational and Research Centre for Animal Husbandry Hofgut Neumühle (Münchweiler an der Alsenz, Germany). All experimental procedures were approved by the Provincial Government of Coblenz, Germany (23 177-07/G 14-20-050). 


\section{Animals and Experimental Design}

A total of 30 multiparous Holstein dairy cows kept in a freestall barn equipped with weighing troughs were randomly allocated to 2 groups. One group was fed a TMR (control group). The second group (NA group) was fed the same diet and received Niashure (Balchem, New Hampton, NY) at $79 \mathrm{mg} / \mathrm{kg}$ of BW (i.e., $55 \mathrm{~g}$ of Niashure per 700-kg cow per d), which is equivalent to $47 \mathrm{mg}$ of NA per $\mathrm{kg}$ of BW at the duodenum considering an amount of $65 \%$ of NA in Niashure (information from the supplier) and a ruminal stability of $92 \%$ (own analysis, see below). The selected dosage was comparable to the NA dosage used in earlier studies with rats and sheep where NA supplemented at approximately 30 to $50 \mathrm{mg} / \mathrm{kg}$ of $\mathrm{BW}$ induced muscle fiber switching in obese Zucker rats (Ringseis et al., 2013), sheep (Khan et al., 2013a), and growing pigs (Khan et al., 2013b). The Niashure dosage was adapted to the cow BW once per week beginning $21 \mathrm{~d}$ before expected calving date and until $21 \mathrm{~d}$ postpartum (p.p.). The Niashure was mixed into $500 \mathrm{~g}$ of pressed sugar beet pulp and fed once daily at $0800 \mathrm{~h}$ in feed fences to ensure individual and complete intake; cows of the control grouped received $500 \mathrm{~g}$ of pressed sugar beet pulp only. On average, at the start of the trial, the pregnant cows of the control and NA group had a BW of $771 \pm 19$ and $768 \pm 29 \mathrm{~kg}$ (mean \pm SEM; $P=0.94)$, a BCS of 3.4 \pm 0.06 and $3.3 \pm 0.06(P=0.13)$, a feed intake of 14.2 \pm 0.6 and $13.9 \pm 0.5 \mathrm{~kg}$ of $\mathrm{DM} / \mathrm{d}(P=0.67)$, energy balance of $34.2 \pm 3.8$ and $35.4 \pm 3.4 \mathrm{MJ}$ of $\mathrm{NE}_{\mathrm{L}} / \mathrm{d}(P$ $=0.82)$, and lactation number of $3.2 \pm 0.34$ and $2.9 \pm$ $0.29(P=0.42)$. The cows had free access to feed and water, and feed was provided twice daily at 7 and 14 h. Antepartum and postpartum diets (Table 1) were formulated to meet requirements (GfE, 2001).

\section{Data and Sample Collection}

Feed ingredient and TMR samples were collected every month, and silage DM was determined weekly and adjusted in ration formulations. The DMI was recorded with automatic weighing troughs (Roughage Intake Control System, Marknesse, the Netherlands) except during the first 5 to $7 \mathrm{~d}$ after calving where cows were kept in small groups separately from the herd. The BW of cows was recorded once per week antepartum (a.p.), and twice daily p.p., with an automatic scale (GEA Farm Technologies GmbH, Bönen, Germany). Cows were milked twice daily at 0430 and $1530 \mathrm{~h}$. A composite sample of morning and evening milk was sampled for the first time at $7.2 \pm 0.9 \mathrm{~d}$ p.p. and afterward once per week, and the bronopol (2-bro- mo-2-nitropropane-1,3-diol) preservative-treated milk samples were analyzed for milk fat, protein, and lactose by infrared spectrophotometry using a MilkoScan FT+ (Foss Analytical A/S, Hillerød, Denmark) at the laboratory of Landeskontrollverband Rheinland-Pfalz (BadKreuznach, Germany). For milk protein, the reference method for MilkoScan calibration was CP determination by the Kjeldahl method. Approximately $9 \mathrm{~mL}$ of blood was collected at 21, 14, and $7 \mathrm{~d}$ before expected calving and at wk 1, 2, 3, 5, and 9 p.p. between 0700 and $0800 \mathrm{~h}$ (i.e., after milking and before feeding) from the tail vain (vena caudalis mediana) into containers containing EDTA (S-Monovette $9 \mathrm{~mL}$ K3E, Sarstedt, Nümbrecht, Germany), kept in ice water for maximum $1 \mathrm{~h}$, centrifuged at $2,000 \times g$ for $10 \mathrm{~min}$ at $4^{\circ} \mathrm{C}$, and the plasma was harvested and stored at $-20^{\circ} \mathrm{C}$ until analysis. Liver samples were collected 1 and 3 wk p.p. at $0900 \mathrm{~h}$ between the 9 th and 10 th ribs, approximately

Table 1. Ingredient and nutrient composition of the TMR used as experimental diets during the dry period and lactation (\% of DM)

\begin{tabular}{|c|c|c|}
\hline Item & Antepartum & $\begin{array}{l}\text { Postpartum } \\
\text { (1-63 DIM) }\end{array}$ \\
\hline \multicolumn{3}{|l|}{ Ingredient, $\%$ of DM } \\
\hline Corn silage & 34.7 & 19.3 \\
\hline Grass silage & 31.3 & 18.7 \\
\hline Pressed sugar-beet pulp silage & - & 12.5 \\
\hline Grass hay & 6.9 & 7.5 \\
\hline Straw & 6.3 & 3.0 \\
\hline Barley & 5.4 & 8.9 \\
\hline Grain maize & 4.7 & 12.1 \\
\hline Soybean meal & 2.8 & 6.9 \\
\hline Rapeseed meal & 5.8 & 8.9 \\
\hline Cattle salt & 0.25 & 0.43 \\
\hline Urea & 0.32 & 0.25 \\
\hline Limestone & 0.24 & 0.31 \\
\hline Mineral feed ${ }^{1,2}$ & 0.50 & 0.43 \\
\hline Mineral feed (dry cows) ${ }^{2}$ & 0.80 & - \\
\hline Feed fat & - & 0.9 \\
\hline \multicolumn{3}{|l|}{ Nutrient, $\%$ of DM } \\
\hline $\mathrm{DM}$ & 35.6 & 44.8 \\
\hline Crude ash & 6.7 & 5.9 \\
\hline $\mathrm{CP}$ & 13.5 & 16.6 \\
\hline Crude fat & 2.9 & 3.0 \\
\hline Crude fiber & 18.3 & 15.2 \\
\hline Ash-free NDF & 40.8 & 34.9 \\
\hline Ash-free ADF & 23.3 & 19.2 \\
\hline $\mathrm{NE}_{\mathrm{L}}, \mathrm{MJ}$ & 6.4 & 7.0 \\
\hline
\end{tabular}

${ }^{1}$ The mineral feed (Rindamin K11, Schaumann, Pinneberg, Germany) supplied per kilogram of postpartum diet: $\mathrm{Ca}, \mathrm{P}, \mathrm{Na}, 0.39 \mathrm{~g} ; \mathrm{Mg}, 0.43$ g; Zn, $43 \mathrm{mg}$; Mn, $26 \mathrm{mg}$; Cu, $6.5 \mathrm{mg}$; Co, $0.26 \mathrm{mg}$; J, $0.87 \mathrm{mg}$; Se, $0.23 \mathrm{mg}$; vitamin A, 4,343 IU, vitamin $\mathrm{D}_{3}, 652 \mathrm{IU}$; vitamin $\mathrm{E}, 26 \mathrm{mg}$.

${ }^{2}$ The mineral feeds in the antepartum diet, including Rindamin K11 and the mineral feed for dry cows (Rindavital VK C Plus ATG, Schaumann), supplied per kilogram of diet: Ca, P, Na, $0.45 \mathrm{~g} ; \mathrm{Mg}, 1.3$ g; vitamin A, 12,970 IU; vitamin E, $110 \mathrm{mg}$; vitamin $\mathrm{D}_{3}, 1,228 \mathrm{IU}$; Lcarnitine, $96 \mathrm{mg}$; biotin, $0.80 \mathrm{mg}$; Zn, $90 \mathrm{mg}$; Mn, $46 \mathrm{mg}$; Cu, $15.5 \mathrm{mg}$, Co, $0.62 \mathrm{mg}$; J, $1.80 \mathrm{mg}$; Se, $0.48 \mathrm{mg}$; clinoptilolite, $0.8 \mathrm{~g}$; citric acid, $10.0 \mathrm{mg}$; butylated hydroxytoluene, $6.77 \mathrm{mg}$; propyl gallate, $2.39 \mathrm{mg}$; ethoxyquin, $0.96 \mathrm{mg}$. 
$15 \mathrm{~cm}$ below the transverse processes using a self-made barbed 12 -gauge $\times 27 \mathrm{~cm}$ biopsy needle. The area was shaved, aseptically prepared with $70 \%$ ethanol, and the injection site and the peritoneum were anesthetized with $5 \mathrm{~mL}$ of Procamidor $(20 \mathrm{mg} / \mathrm{mL}$; WDT, Garbsen, Germany). After $5 \mathrm{~min}$, an incision $(1 \mathrm{~cm})$ was made with a scalpel and the biopsy needle was inserted cranioventrally toward the liver, and approximately 0.5 to $1 \mathrm{~g}$ of tissue was collected. The incision site was treated topically with oxytetracyclin spray (Engemycin, MSD Animal Health GmbH, Unterschleissheim, Germany). Muscle biopsies were taken at 1 and 3 wk p.p., alternating on the left and right body side, from the longissimus lumborum (LD), semitendinosus (ST), and semimembranosus (SM). The muscles were identified by palpation and the biopsy site was shaved, aseptically prepared with $70 \%$ ethanol, and anesthetized with 5 $\mathrm{mL}$ of Procamidor. After $5 \mathrm{~min}$, an incision $(0.5 \mathrm{~cm})$ was made through the skin with a scalpel, and the coaxial cannula (HCC12130, 11 G, 93 mm; BIP Biomed Instrumente and Produkte GmbH, Türkenfeld, Germany) was inserted cranioventrally until about $5 \mathrm{~cm}$ depth and approximately $0.5 \mathrm{~g}$ of tissue was collected. Liver and muscle tissues were snap-frozen in liquid $\mathrm{N}_{2}$ and stored at $-80^{\circ} \mathrm{C}$ until analysis. The cows received the anti-inflammatory drug Rifen $(3 \mathrm{~mL} / 100 \mathrm{~kg}$ of BW; Vetoquinol GmbH, Ravensburg, Germany) for $3 \mathrm{~d}$ after biopsy collection.

The BCS was determined every 2 wk by 2 trained investigators on a 1 to 5 scale according to Wildman et al. (1982) and Edmonson et al. (1989).

\section{Determination of Rumen Stability of Niashure}

The rumen degradability of Niashure was determined with 8 dry Holstein-Friesian cows fed $6 \mathrm{~kg}$ of DM of a diet consisting of grass silage (45\%), maize silage (25\%), hay $(10 \%)$, and concentrate $(20 \%)$, and equipped with ruminal fistulas. The in sacco technique according to Ørskov and McDonald (1979) was used as described in Metwally et al. (2015) and $5 \mathrm{~g}$ of Niashure were weighed into the $10 \times 20 \mathrm{~cm}$ nylon bags with a pore size of $53 \mu \mathrm{m}$, and 2 bags per cow and incubation time were incubated for $2,4,6,9,12,24,48,72$, and $96 \mathrm{~h}$. The NA concentrations in Niashure and in the bag residues was determined by titration with $\mathrm{NaOH}$ (AOAC method no. 944.13; AOAC International, 2006). The NA losses after incubation were calculated as the difference between initial weight and residual weight after incubation and the potential ruminal degradability of Niashure as well as the effective ruminal degradability at assumed passage rates of 4,6 , and $8 \%$ per $\mathrm{h}$ was calculated.

\section{Laboratory Analyses}

The feed samples were analyzed by infrared spectrophotometry at the Agricultural Investigation and Research Institute (LUFA; Speyer, Germany) for DM, crude ash, CP, crude fat, ash-free NDF, ash-free ADF, $\mathrm{ME}$, and $\mathrm{NE}_{\mathrm{L}}$.

In plasma of cows, $\mathrm{NA}$ and its 2 main metabolites nicotinamide (NAM) and nicotinuric acid (NUA) were determined by HPLC-MS/MS according to Liu et al. (2012) with modifications as described by Scholz et al. (2014), and nicotinamide-D4 (Cambridge Isotope Laboratories, Tewksbury, MA) was used as internal standard. For NAM, the coefficient of variation was $5.5 \%$ for one sample measured on 5 successive days and $3.6 \%$ when measured on $1 \mathrm{~d}$. The recovery rate was 92.4 to $97.1 \%$. The limit of detection and the limit of quantification were 0.025 and $0.05 \mu \mathrm{g} / \mathrm{L}$, respectively, for all metabolites.

Plasma concentrations of TG, NEFA, and BHB were determined with the Fluitest TG Kit (Analyticon, Lichtenfels, Germany), the NEFA-HR(2) Kit (Wako, Richmond, VA) and the Autokit 3-HB (Wako). Liver TG were determined with the Fluitest TG Kit as well in liver extracts which were prepared as follows. About $50 \mathrm{mg}$ of liver tissue was homogenized with 0.5 $\mathrm{mL}$ of hexane:isopropanol $(3: 2, \mathrm{vol} / \mathrm{vol})$ at $30 \mathrm{~Hz}$ for 3 min with a TissueLyzer (Qiagen, Hilden, Germany) and extracted for $30 \mathrm{~min}$ in an ultrasonic bath. After centrifugation $\left(1,000 \times g, 15^{\circ} \mathrm{C}, 10 \mathrm{~min}\right)$, the upper fat-containing phase was evaporated to dryness under $\mathrm{N}_{2}$ at $37^{\circ} \mathrm{C}$ and resuspended in isopropanol.

Total RNA was isolated from approximately $18 \mathrm{mg}$ of liver and $27 \mathrm{mg}$ of muscle tissue using Trizol reagent (Invitrogen) according to the manufacturer's protocol, and RNA concentration and purity were estimated from the optical density at 260 and $280 \mathrm{~nm}$, respectively, using an Infinite $200 \mathrm{M}$ microplate reader and a NanoQuant Plate (both from Tecan, Männedorf, Switzerland) and RNA was stored at $-80^{\circ} \mathrm{C}$. Exemplarily, RNA quality in each 2 liver and muscle RNA samples was determined with an Agilent 2100 Bioanalyzer and the Agilent RNA 6000 Nano Kit (Agilent, Santa Clara, CA) and RNA integrity number values were 7.1 and 7.2 for liver RNA and 7.7 and 7.2 for muscle RNA. The cDNA was synthesized from $1.2 \mu \mathrm{g}$ of total RNA using oligo(dT) primers according to Zeitz et al. (2016). The cDNA was diluted 1:2 with DNase/RNase free water and stored at $-20^{\circ} \mathrm{C}$. The quantitative PCR was carried out on a Rotorgene 2000 system (Corbett Research, Mortlake, Australia) using $2 \mu \mathrm{L}$ of cDNA combined with $8 \mu \mathrm{L}$ of a mixture composed of $5 \mu \mathrm{L}$ of KAPA SYBR FAST qPCR Universal Mastermix (Peqlab, Erlangen, Germa- 
ny), $0.2 \mu \mathrm{L}$ each of $10 \mu M$ forward and reverse primers, and 3.6 $\mu \mathrm{L}$ of DNase/RNase-free water in 0.1-mL tubes (Ltf Labortechnik, Wasserburg, Germany; Zeitz et al., 2016). Gene-specific primer pairs were from Schlegel et al. (2012a) or were designed using PRIMER3 and BLAST and obtained from Eurofins MWG Operon (Ebersberg, Germany; Supplemental Table S1; https:// doi.org/10.3168/jds.2018-14490). The amplification of a single product of the expected size was approved using 2\% agarose gel electrophoresis stained with GelRed nucleic acid gel stain (Biotium Inc., Hayward, CA). The $\mathrm{Ct}$ values of target and reference genes were obtained using Rotorgene Software 5.0 (Corbett Research). All cycle threshold $(\mathrm{Ct})$ values were transformed into relative quantification data using the $2^{-\Delta \mathrm{Ct}}$ equation (Livak and Schmittgen, 2001). The highest relative quantities for each gene were set to 1 . These expression values of target genes were normalized using the GeNorm normalization factor calculated as the geometric mean of expression data (relative quantities) of the 3 to 4 most stable of the tested reference genes (Vandesompele et al., 2002). The $\mathrm{M}$ values were 0.38 (liver) and $<1.04$ (muscle; target $<1.5$ ), and the $\mathrm{V}$ values were $<0.15$ (liver, LD) or 0.16 (ST) and 0.17 (SM; target: $<0.15$; Vandesompele et al., 2002). The normalized expression values data set was corrected for outliers.

For immunohistochemistry, frozen muscle tissue of LD, SM, and ST was embedded in TissueTek OCT Compound (Hartenstain, Würzburg, Germany) and frozen in liquid $\mathrm{N}_{2}$, and stored at $-20^{\circ} \mathrm{C}$ until transverse sections of $20 \mu \mathrm{m}$ thickness were cut on a cryostat microtome at $-18^{\circ} \mathrm{C}$ (Microme $\mathrm{HM} 500$, Microm International GmbH, Walldorf, Germany). Immunofluorescence analysis of myosin heavy chain (MHC) expression was performed according to Bloemberg and Quadrilatero (2012) with primary antibodies BA-F8 (1:50) specific against bovine MYHC $\beta /$ slow (MHCI) and BF-35 (1:100) specific for both MHCI and MHCIIa as determined by Duris et al. (2000). Primary antibodies were purchased from the Developmental Studies Hybridoma Bank (University of Iowa), whereas the secondary antibodies Alexa Fluor 350 goat anti-mouse IgG2b (blue) and Alexa Fluor 488 goat anti-mouse IgG1 (green) were purchased from Thermo Fisher Scientific (Waltham, MA). The muscle fibers stained blue by BA-F8 were counted as slow-twitch MHCI fibers, those stained green by MF-35, but not by BA-F8 as the intermediate MHCIIa fibers, and the nonstained muscle fibers were counted as the fast-twitch MHC IIx fibers, the third MHC isoform expressed in muscles of adult cattle (Duris et al., 2000; Toniolo et al., 2005) on the microscope DM 5500 B with camera DFC 340 FX
(Leica, Wetzlar, Germany) with fluorescent light (excitation 320-400 nm and emission $430-510 \mathrm{~nm}$ for blue filter, excitation $440-520 \mathrm{~nm}$, and emission $497-557 \mathrm{~nm}$ for green filter). The photographs taken with the different filters were combined into one image with Microsoft Image Composite Editor (Microsoft Corp., Redmond, WA), and a mean of 450 but minimum of 100 muscle fibers per muscle and animal were counted and assigned to a fiber type with the software Fiji (Schindelin et al., 2012).

Concentrations of free carnitine and acetyl carnitine in liver were determined with tandem mass spectrometry and deuterated carnitine-d3 (Cambridge Isotype Laboratories, Andover, MA) as an internal standard according to Hirche et al. (2009). For that $100 \mathrm{mg}$ of liver tissue was lyophilized (Christ Gamma 1-20 LMC2; Martin Christ Gefriertrocknungsanlagen $\mathrm{GmbH}$, Osterode am Harz, Germany) and homogenized with $0.5 \mathrm{~mL}$ of methanol/water $(1: 2)$ at $30 \mathrm{~Hz}$ for $4 \mathrm{~min}$, incubated for $20 \mathrm{~min}$ in an ultrasonic bath, further incubated at $50^{\circ} \mathrm{C}$ and $650 \mathrm{U} / \mathrm{min}$ for $30 \mathrm{~min}$ (ThermoShaker TS1, Biometra, Göttingen, Germany), centrifuged $\left(10^{\circ} \mathrm{C}, 10 \mathrm{~min}, 21,000 \times \mathrm{g}\right)$, and $40 \mu \mathrm{L}$ of the supernatant was combined and mixed with methanol/ internal standard $(200 \mu \mathrm{L})$, incubated at $4^{\circ} \mathrm{C}$ for 10 min, and centrifuged $\left(15^{\circ} \mathrm{C}, 10 \mathrm{~min}, 21,000 \times g\right)$, and the supernatant was used for analysis.

\section{Statistical Analysis}

Data were statistically analyzed using mixed models with repeated measures over time using the software $\mathrm{R}$ version 3.1.1 (R Development Core Team, 2011, Vienna, Austria) and the packages nlme, lme4, lmerTest, and lsmeans. A mixed linear model (function lmer) with unstructured variance-covariance structure was used for accounting for the repeated measures and unbalanced group sizes for the treatments. The following model was applied for the analysis:

$$
\mathrm{Y} \sim \text { treatment }+ \text { week }+ \text { treatment:week }+ \text { animal, }
$$

where treatment and week and their interaction where treated as factors with fixed effects, and animal was treated as a factor with random effect to account for the dependency of the repeated measures over time. For time series data, data from wh 1 and 3 or 1 to 3 p.p. were included in the analysis and week was treated as the repeated measure. For analysis of data sets with only one time point, treatment was considered as fixed and animal as random effect and the following model was applied for the analysis: 


$$
\mathrm{Y} \sim \text { treatment + animal, }
$$

using the function lme, package nlme. Pair-wise comparisons were done using the Hochberg test and the function lsmeans. Separate standard errors of the mean for each mean are presented because homogeneity of variances was not assumed in the linear model, and sample sizes for the 2 treatments were unbalanced because 1 cow from the niacin treatment became ill and was excluded from the trial.

\section{RESULTS}

\section{Rumen Stability of Niashure}

The ruminal stability of Niashure was $89.5 \pm 0.89$, $91.9 \pm 0.64$, and $93.3 \pm 0.52 \%($ mean $\pm \mathrm{SE} ; \mathrm{n}=8)$ at assumed feed passage rates of 4,6 , and $8 \%$ per h, respectively.

\section{Animal Performance}

Feed intake, milk and milk protein yield, milk urea concentration, and the extent of the NEB were similar in cows treated with NA and control cows (Table 2). Milk fat percentage and milk fat yield in wk 1 to 3 of lactation were lower in cows supplemented with NA than in control cows (Table 2). Correspondingly, milk energy content, and the fat:protein ratio showed a tendency toward decreased values in cows fed NA compared with control cows (Table 2). The BW and BCS were similar in both groups of cows p.p. (Table $2)$. In addition, feed intake 1 wk a.p. was similar in the control $(11.8 \pm 0.61 \mathrm{~kg}$ of DM) and NA groups $(11.6 \pm$ $0.46 \mathrm{~kg}$ of DM; $P=0.85)$.

\section{Plasma and Liver Metabolic Parameters}

Cows treated with NA had an approximately 4-fold higher concentration of NAM, the main metabolite of $\mathrm{NA}$, in plasma in wk 1 and 3 of lactation compared with control cows (Figure 1), and NA and NUA were below the detection limit. However, NA supplementation neither affected plasma TG and NEFA concentrations nor liver TG concentrations in wk 1 and 3 p.p (Figures 1 and 2). Liver mRNA concentrations of HCAR2 were similar in both groups in wk 1 and 3 p.p. as well [data not shown; $P$ (treatment $)=0.74 ; P($ treatment $\times$ week $)$ $=0.80]$. Plasma carnitine concentrations in wk 3 a.p. to 9 p.p also remained unaffected by NA supplementation $(2.49 \pm 0.17$ and $2.56 \pm 0.14 \mu \mathrm{mol} / \mathrm{L}$ in control and NA group, respectively, $P=0.76$ ). Likewise, liver carnitine concentrations in wk 1 and 3 p.p. were similar in cows of the control group $(35.9 \pm 3.30)$ and the NA group $(29.4 \pm 1.67 ; P=0.07)$. Plasma BHB concentrations, however, were affected by NA treatment in wk 1 to 3 p.p. (Figure 2). The concentrations of BHB were lower by 18 and $26 \%$ at 2 and 3 wk p.p. in cows supplemented with NA than in control cows (Figure 2). After cessation of niacin treatment (i.e., after wk 3 p.p.), plasma TG, NEFA, and BHB concentrations were similar in both groups (Figure 2).

\section{Muscle Fiber Switching}

The percentages of type I fibers and the ratio of type II to type I fibers in the LD, ST, and SM muscles in wk 1 and 3 p.p. were not influenced by NA treatment (Table 3, Figure 3). In the SM muscle, the percentage of IIa and IIx fibers (Table 3) and the ratio of IIx to IIa fibers (data not shown) also remained unaffected by

Table 2. Performance of dairy cows fed either a control diet (control) or a diet supplemented with rumen-protected niacin (niacin) ${ }^{1}$

\begin{tabular}{|c|c|c|c|c|c|}
\hline \multirow[b]{2}{*}{ Item } & \multicolumn{2}{|c|}{ 1-3 wk p.p. } & \multicolumn{3}{|c|}{$P$-value } \\
\hline & Control & Niacin & Treatment & Week & Treatment $\times$ week \\
\hline BCS & $3.17 \pm 0.28$ & $3.09 \pm 0.22$ & 0.32 & 0.044 & 0.40 \\
\hline DMI, kg & $16.0 \pm 0.8$ & $15.6 \pm 0.6$ & 0.66 & $<0.001$ & 0.28 \\
\hline Energy balance, $\mathrm{MJ}$ of $\mathrm{NE}_{\mathrm{L}} / \mathrm{d}$ & $-72.8 \pm 5.9$ & $-61.5 \pm 8.9$ & 0.21 & $<0.001$ & 0.72 \\
\hline Milk yield, kg & $38.6 \pm 1.6$ & $36.2 \pm 1.9$ & 0.25 & $<0.001$ & 0.06 \\
\hline Milk fat, $\mathrm{kg} / \mathrm{d}$ & $2.06 \pm 0.13$ & $1.76 \pm 0.13$ & 0.04 & 0.03 & 0.36 \\
\hline Milk proteint, kg/d & $1.29 \pm 0.07$ & $1.22 \pm 0.07$ & 0.28 & $<0.001$ & 0.03 \\
\hline Milk fat:protein ratio & $1.61 \pm 0.09$ & $1.45 \pm 0.08$ & 0.06 & 0.14 & 0.58 \\
\hline Milk urea, mg/L & $188 \pm 9$ & $177 \pm 8$ & 0.18 & 0.01 & 0.50 \\
\hline Milk energy, MJ/d & $148 \pm 7$ & $130 \pm 8$ & 0.05 & 0.08 & 0.24 \\
\hline
\end{tabular}

${ }^{1}$ Mean \pm SEM are displayed $(\mathrm{n}=15$ and 14 animals in the control and niacin group). For BW, DMI, and energy balance, data from wk 1 postpartum (p.p.) were missing, and in these cases, data from wk 2 to 3 p.p. are shown. 
NA treatment. However, the percentage of oxidativeglycolytic type IIa fibers was higher and those of glycolytic type IIx fibers as well as the ratio of type IIx to type IIa fibers was lower in the ST muscle of cows supplemented with NA than in control cows (Table 3, Figure 3 ). In the LD muscle, there were tendencies toward an increase of IIa fibers $(P=0.05)$ and a reduction of IIx fibers $(P=0.10$; Table 3, Figure 3$)$.

In line with the data on muscle fiber typing, relative mRNA concentrations of the MHC isoform $\mathrm{MYH}^{\text {r }}$, expressed in type I fibers, in wk 1 and 3 p.p. were unaffected by NA treatment in the LD and SM muscles; however, the relative mRNA concentrations of $M Y H 7$ were higher in the ST muscle in the NA group compared with the control group (Table 4). In addition, relative mRNA concentrations of the 2 fast $\mathrm{MHC}$ isoforms MYH1 and MYH2 remained unaffected by NA treatment in the SM and ST muscles (Table 4). In the LD muscle, relative mRNA concentration of the isoform MYH1, expressed in glycolytic type IIx fibers, was lower in the NA group compared with the control group (Table 4).

\section{Expression of Key Regulators of Muscle Fiber Transition and Genes Involved in Energy Production in Skeletal Muscle}

Relative muscle mRNA concentrations of the HCAR2 in wk 1 and 3 p.p. were similar in both groups $(P>$ 0.10 ; data not shown). Likewise, relative mRNA concentration of PPARD, one of the key regulators of muscle fiber transition, in wk 1 and 3 p.p. was not different between cows supplemented with NA and control cows in all 3 muscles considered (Figure 4A, 4B, 4C). Relative mRNA concentration of PPARGC1A, another important regulator of muscle fiber transition, in LD and SM muscles also was not different between the 2 groups of cows (Figure 4A, 4C). In contrast, in ST muscle, relative mRNA concentration of PPARGC1A in wk 1 and 3 p.p. was higher in cows treated with NA
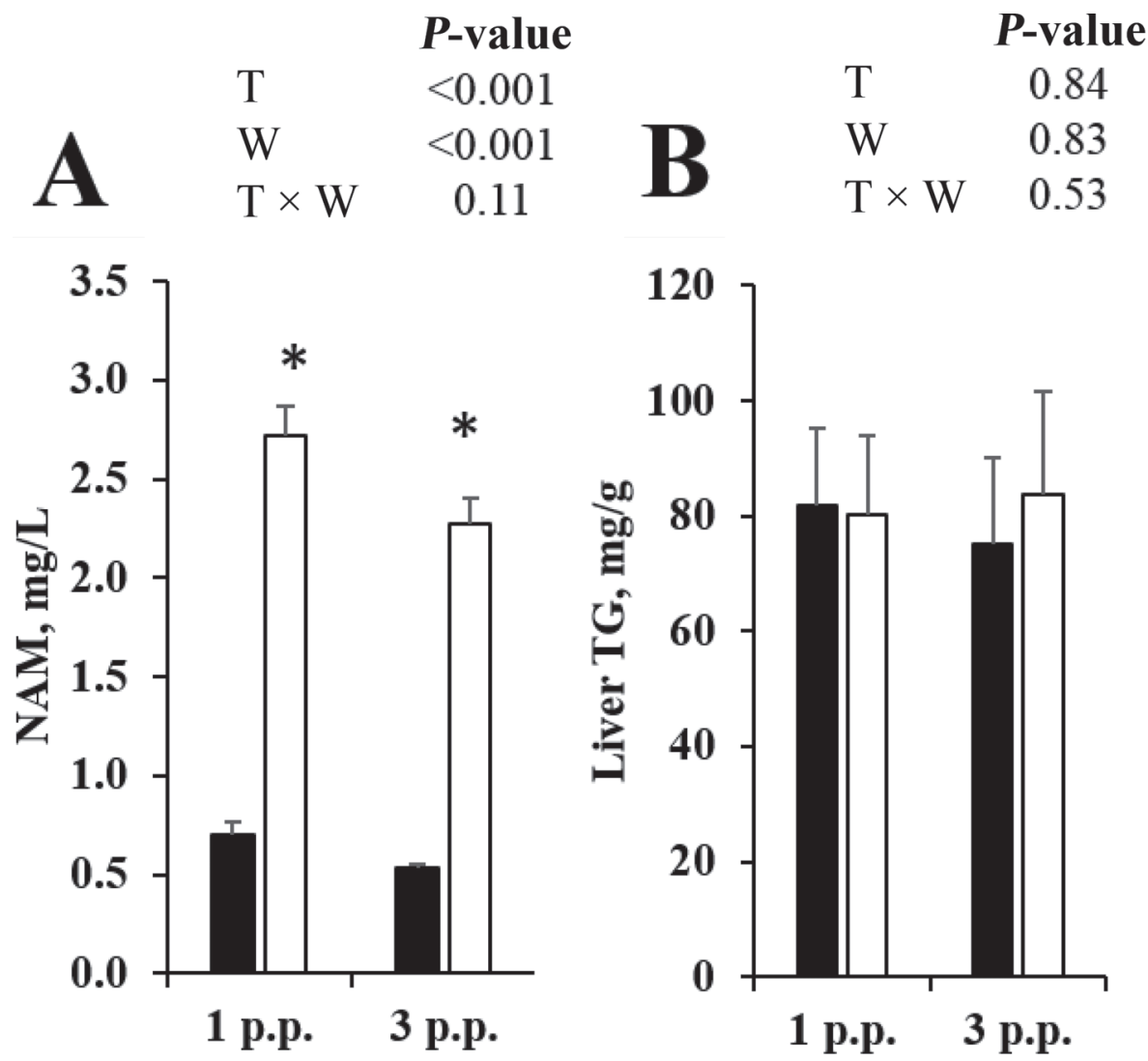

Control $\square$ Niacin

Figure 1. Concentrations of nicotinamide (NAM) in the plasma (A) and triglycerides (TG) in the liver (B) of dairy cows fed either a control diet (control) or a diet supplemented with rumen-protected niacin (niacin; $\mathrm{n}=15$ and 14 animals in the control and niacin group; mean $\pm \mathrm{SEM}) .{ }^{*}$ Denotes a difference $(P<0.05)$ between the control and niacin group at the respective time point. $\mathrm{T}=$ treatment; $\mathrm{W}=$ week; $\mathrm{T} \times$ $\mathrm{W}=$ interaction of treatment and week. 

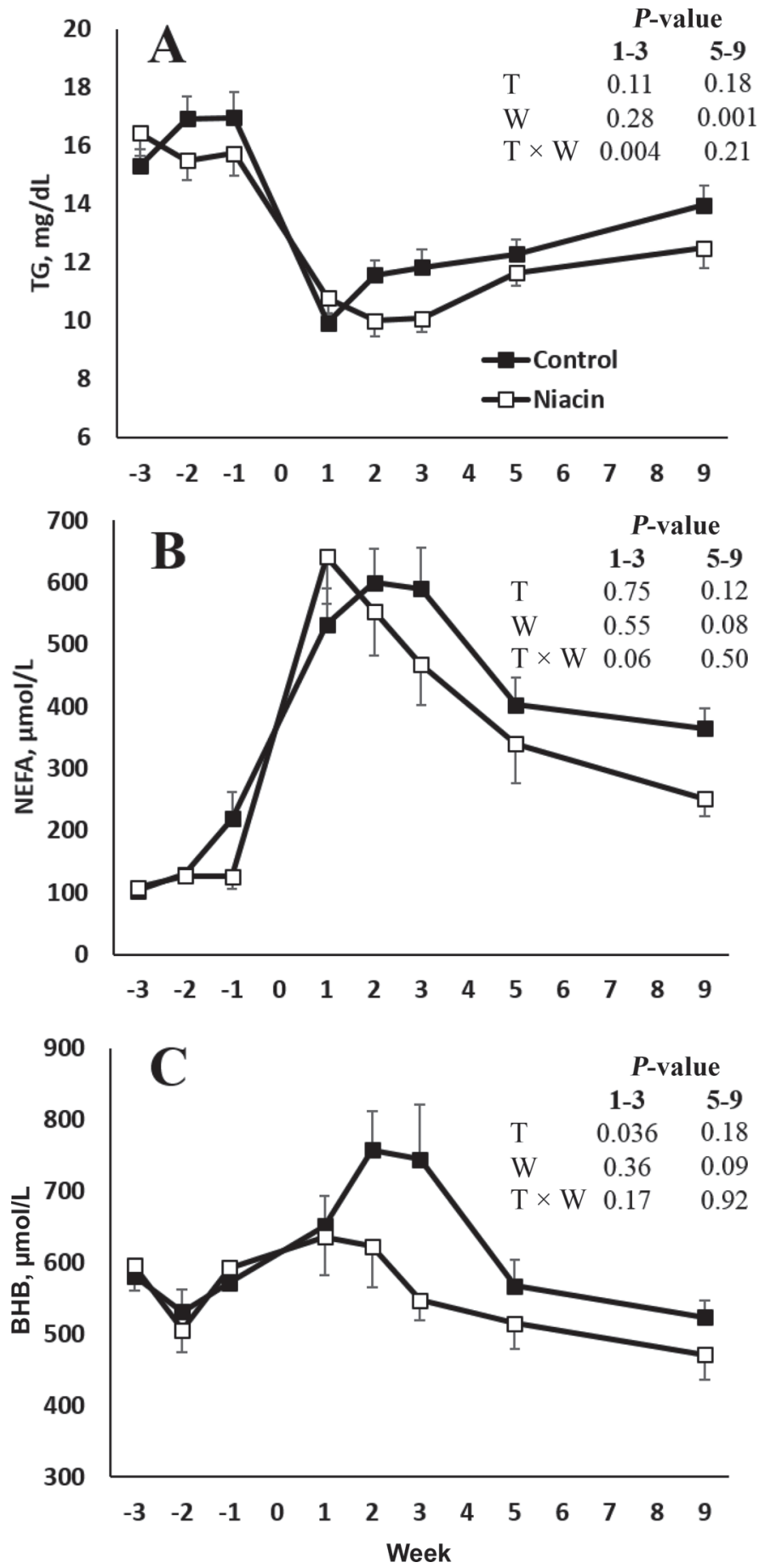

Figure 2. Concentrations of triglycerides (TG; A), nonesterified fatty acids (NEFA; B), and BHB (C) in the plasma of dairy cows fed either a control diet (control) or a diet supplemented with rumenprotected niacin (niacin; $\mathrm{n}=15$ and 14 animals in control and niacin group; mean $\pm \mathrm{SEM})$. The $\mathrm{x}$-axis shows wk 3,2 , and 1 antepartum $(-3$ to -1$)$ and wk $1,2,3,5$, and 9 postpartum (p.p.; 1 to 9$)$. $\mathrm{T}=$ treatment; $\mathrm{W}=$ week; $\mathrm{T} \times \mathrm{W}=$ interaction of treatment and week. The statistical analysis included wk 1 to 3 p.p. (1-3) to investigate effects of niacin in the challenging period of early lactation during niacin treatment, and wk 5 to 9 p.p. (5-9) to investigate if effects of niacin persist after cessation of treatment after wk 3 p.p. than in control cows (Figure 4B). In ST muscle, relative mRNA concentrations of 8 out of 9 genes involved in oxidative energy production including genes involved in FA transport into cell and mitochondrion (SLC27A1/ FATP1, CPT1B, SLC25A20/CACT), in mitochondrial FA oxidation $(A C A D L)$, in the transport of carnitine into the cell (SLC22A4/OCTN1, SLC22A5/OCTN2) as well as tricarboxylic acid cycle and oxidative phosphorylation (SDHA, COX6A2) were not different between the NA group and the control group (Table 5). Among genes involved in oxidative energy production, COX 411 was the only gene that was upregulated in cows treated with NA compared with control cows (Table 5). Relative mRNA concentrations of genes involved in glucose utilization (SLC2A4/GLUT4, PFKM) in ST muscle were also similar in both groups of cows (Table 5 ). In $\mathrm{LD}$ and SM muscle, relative mRNA concentrations of all the genes involved in fatty acid uptake and oxidation, carnitine transport, tricarboxylic acid cycle and oxidative phosphorylation, and glucose utilization were not different between cows supplemented with NA and control cows (data not shown).

\section{Expression of Genes Involved in Fatty Acid Utilization, Lipogenesis, Ketogenesis, and the Unfolded Protein Response in the Liver}

To assess whether NA treatment had an influence on hepatic lipid metabolism and ketogenesis, we determined mRNA concentrations of several genes involved in fatty acid utilization, lipogenesis, and ketogenesis in liver samples of wk 1 and 3 p.p. Relative mRNA concentrations of PPARA, the key regulator of $\beta$-oxidation and ketogenesis, and genes involved in fatty acid uptake (CD36), fatty acid oxidation (CPT1A, SLC25A20/ $C A C T, A C A D M, A C A D L)$, carnitine uptake into the cell (SLC22A5/OCTN2), and classical genes involved in ketogenesis (ACAT1, HMGCS2) were not different between cows supplemented with NA and control cows (Table 6). Relative mRNA concentrations of SREBF1, the key regulator of lipogenesis, as well as genes involved in fatty acid and TG synthesis (FASN, GPAM, $D G A T 2)$ were also not different between the 2 groups of cows (Table 6). However, relative mRNA concentration of fibroblast growth factor 21 (FGF21), a regulator of ketogenesis, was reduced in the liver of cows supplemented with NA (Table 6). As FGF21 is a target gene of the unfolded protein response (UPR), which is triggered by endoplasmic reticulum (ER) stress, we determined several genes of the UPR to find out whether NA affected that pathway. However, mRNA concentrations of various genes of the UPR were not influenced by treatment with NA (Table 6). 
Table 3. Muscle fiber type composition in longissimus lumborum, semitendinosus, and semimembranosus of dairy cows fed either a control diet (control) or a diet supplemented with rumen-protected niacin (niacin $)^{1}$

\begin{tabular}{|c|c|c|c|c|c|c|c|}
\hline \multirow[b]{2}{*}{ Item } & \multicolumn{2}{|c|}{1 wk postpartum } & \multicolumn{2}{|c|}{3 wk postpartum } & \multicolumn{3}{|c|}{$P$-value } \\
\hline & Control & Niacin & Control & Niacin & Treatment & Week & Treatment $\times$ week \\
\hline \multicolumn{8}{|c|}{ Longissimus lumborum } \\
\hline Type I, \% & $32.9 \pm 2.06$ & $33.3 \pm 1.64$ & $30.6 \pm 1.34$ & $31.2 \pm 0.97$ & 0.75 & 0.15 & 0.97 \\
\hline Type IIa, \% & $33.0 \pm 2.45$ & $34.6 \pm 1.38$ & $30.2 \pm 1.97$ & $37.1 \pm 2.10$ & 0.05 & 0.61 & 0.076 \\
\hline Type IIx, \% & $34.1 \pm 3.96$ & $32.1 \pm 2.02$ & $39.2 \pm 1.99$ & $31.7 \pm 2.32$ & 0.10 & 0.21 & 0.20 \\
\hline Type II, \% & $67.1 \pm 2.06$ & $66.7 \pm 1.64$ & $69.4 \pm 1.34$ & $68.8 \pm 0.97$ & 0.75 & 0.15 & 0.97 \\
\hline \multicolumn{8}{|c|}{ Semitendinosus } \\
\hline Type IIa, \% & $30.3 \pm 1.00$ & $36.9 \pm 2.93$ & $32.6 \pm 2.52$ & $36.5 \pm 2.18$ & 0.023 & 0.68 & 0.55 \\
\hline Type IIx, \% & $48.1 \pm 1.61$ & $40.6 \pm 2.67$ & $46.5 \pm 3.71$ & $42.4 \pm 2.55$ & 0.028 & 0.96 & 0.51 \\
\hline Type II, \% & $78.4 \pm 1.68$ & $77.5 \pm 0.74$ & $79.1 \pm 2.24$ & $78.9 \pm 1.60$ & 0.67 & 0.45 & 0.81 \\
\hline \multicolumn{8}{|c|}{ Semimembranosus } \\
\hline Type I, \% & $28.7 \pm 1.63$ & $26.7 \pm 1.22$ & $25.8 \pm 2.46$ & $28.4 \pm 2.17$ & 0.90 & 0.79 & 0.21 \\
\hline Type IIa, \% & $35.2 \pm 1.60$ & $35.0 \pm 1.43$ & $38.3 \pm 2.74$ & $34.4 \pm 1.32$ & 0.55 & 0.29 & 0.40 \\
\hline Type IIx, \% & $36.0 \pm 1.85$ & $38.3 \pm 2.10$ & $35.9 \pm 1.78$ & $37.2 \pm 2.25$ & 0.69 & 0.47 & 0.63 \\
\hline
\end{tabular}

${ }^{1}$ Mean \pm SEM are displayed $(\mathrm{n}=10$ animals per group).

\section{DISCUSSION}

In the present study, we investigated the hypothesis that supplementation of periparturient dairy cows with high dosages of rumen-protected NA induces muscle fiber type switching toward an increase of the oxidative type I fibers in skeletal muscle. The dosage of NA per $\mathrm{kg}$ of BW used in this study was comparable with the NA dosages used in recent studies with growing rats, sheep, and pigs in which NA treatment caused a muscle fiber transition (Khan et al., 2013a,b; Ringseis et al., 2013). Although the intestinal availability of NiaShure has not been reported in the scientific literature and absorbed amounts of NA are unknown, we have confirmed that plasma NAM concentrations rose several-fold in NA-treated cows compared with control cows. Notably, NA dosages used in this study ( $\geq 55 \mathrm{~g} / \mathrm{d}$ of NiaShure and $\geq 36 \mathrm{~g} / \mathrm{d}$ of NA) as well as plasma NAM concentrations achieved in the cows by NA treatment $(2-3 \mu \mathrm{g}$ of $\mathrm{NAM} / \mathrm{mL}$ of plasma) were higher than in most other studies performed with dairy cows with rumen-protected NA $(24 \mathrm{~g} / \mathrm{d}$ of NiaShure or $16 \mathrm{~g} / \mathrm{d}$ of $\mathrm{NA}, 0.9-1.3 \mu \mathrm{g}$ of $\mathrm{NAM} / \mathrm{mL}$ of plasma in Morey et al., 2011; $12 \mathrm{~g} / \mathrm{d}$ of NiaShure or $7.8 \mathrm{~g} / \mathrm{d}$ of NA in Yuan et al., 2012) and non-rumen-protected NA (typically $6-12 \mathrm{~g} / \mathrm{d}$ of NA and $0.6-1.9 \mu \mathrm{g}$ of NAM/ $\mathrm{mL}$ of plasma in NA-treated cows; reviewed by Niehoff et al., 2009). Because plasma NAM concentrations are elevated during the whole day after a single dose of NiaShure but peak plasma NAM concentrations occur 8 to $10 \mathrm{~h}$ after ingestion (Tienken et al., 2015), the concentrations found in the plasma samples collected $23 \mathrm{~h}$ after NA supplementation in the present study are expected to represent only about two-thirds of the peak NAM concentrations. Also, NA and NUA in plasma probably could not be detected because, during the first hours after ingestion, NA is degraded to NAM, and after saturation of the amidation pathway also to NUA, which is itself rapidly degraded (Inamadugu et al., 2010).

The observation that milk yield remained unaffected while milk fat yield was reduced by NA treatment agrees with findings of Morey et al. (2011) and Yuan et al. (2012) in cows supplemented with NA. In addition, milk yield was unaffected in the majority of studies investigating supplementation of non-rumen-protected NA and milk fat yield was unaffected in most of these studies as well (Niehoff et al., 2009). Generally, dietary NA may exert its effects on milk production either by affecting microbial growth and feed degradation in the rumen or by effects on metabolism (Schwab et al., 2005). An effect of NA on microbial growth is unlikely in the present study considering the low ruminal degradability of NiaShure and thus an estimated ruminal NA supply of only 3 to $4 \mathrm{~g} / \mathrm{d}$. Low dosages of $6 \mathrm{~g}$ of non-rumenprotected NA/d also have not shown effects on production and plasma parameters in a meta-analysis (Schwab et al., 2005). In addition, even $12 \mathrm{~g} / \mathrm{d}$ of NA had only minimal effects on ruminal fermentation and feed degradation (Schwab et al., 2005). It has been assumed that NA reduces milk fat output due to a decrease in adipose tissue lipolysis and a subsequent decrease in plasma NEFA concentrations (Yuan et al., 2012). Plasma NA concentrations after oral supplementation of 6 to $12 \mathrm{~g} / \mathrm{d}$ of non-rumen-protected NA were probably not sufficient to activate the HCAR2 receptor and 


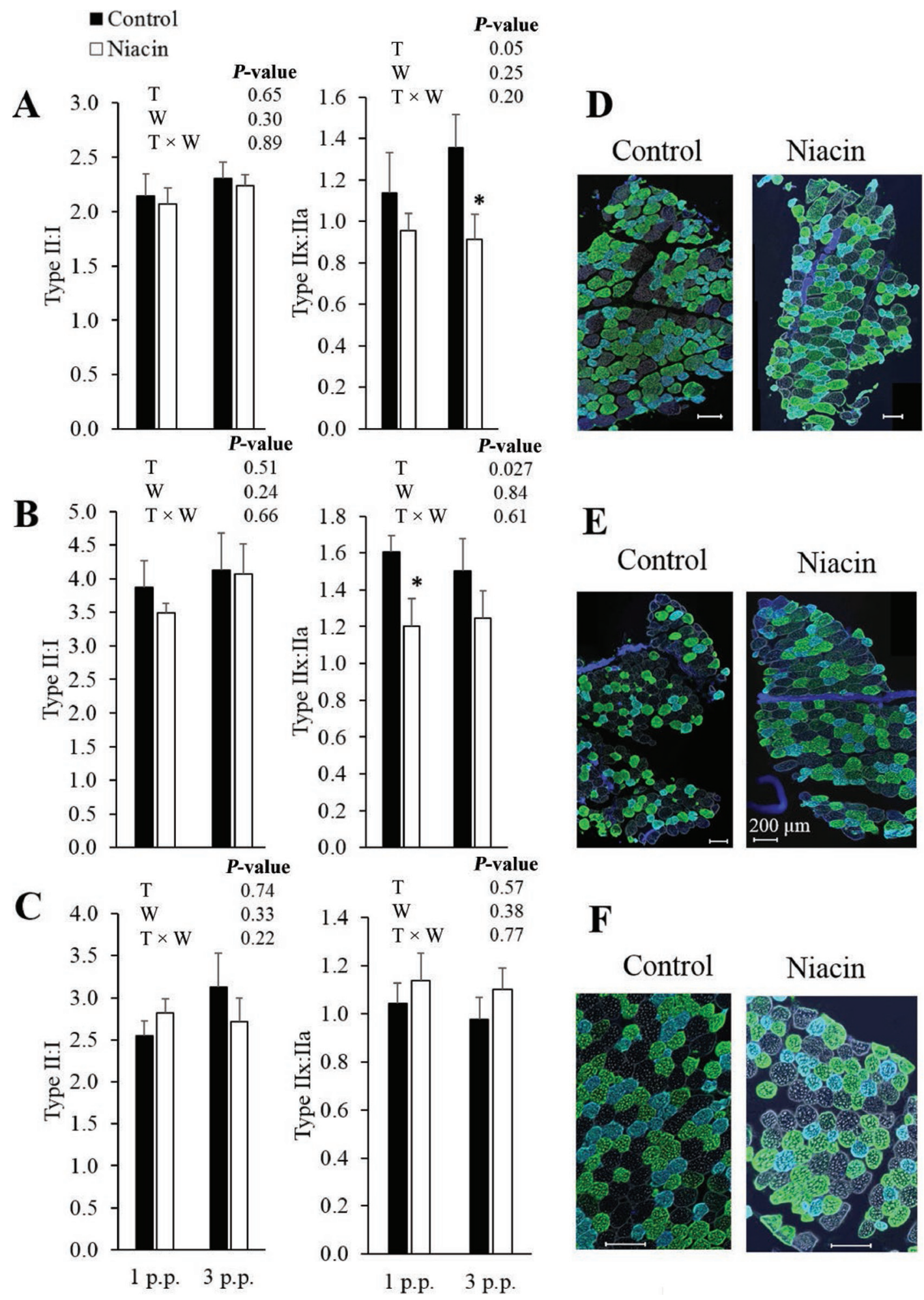

Figure 3. Ratio of type II:I and type IIx:Ila muscle fibers in the longissimus lumborum (A), semitendinosus (B), and semimembranosus (C) of dairy cows fed either a control diet (control) or a diet supplemented with rumen-protected niacin (niacin; $\mathrm{n}=10$ animals per group; mean $\pm \mathrm{SEM})$ at 1 and 3 wk postpartum (p.p.) *Denotes a difference $(P<0.05)$ between the control and niacin group at the respective time point. $\mathrm{T}=$ treatment; $\mathrm{W}=$ week; $\mathrm{T} \times \mathrm{W}=$ interaction of treatment and week. Representative images of cross-sections of the longissimus lumborum (D) at 1 wk p.p., the semitendinosus (E) at 3 wk p.p., and the semimembranosus (F) at 1 wk p.p. incubated with primary antibodies against myosin heavy chain (MHC) I (BA-F8) and MHCIIa (MF-35) followed by incubation with appropriate fluorescent-conjugated secondary antibodies. Fiber types shown include type I (blue), type IIa (green), and type IIx (unstained) fibers. Scale bar $=200 \mu \mathrm{m}$. 
thus to affect adipose tissue lipolysis, which may explain why plasma NEFA concentrations were generally not influenced in such studies (Niehoff et al., 2009). In contrast, Yuan et al. (2012) showed that plasma NEFA concentrations were reduced when supplementing 12 $\mathrm{g} / \mathrm{d}$ of rumen-protected NA. Although, in the present study, plasma NA concentrations in the NA group also should have been high enough to activate the HCAR2 receptor considering the affinity of the receptor for NA (Wise, 2003), neither plasma NEFA not TG concentrations, which are both sources for milk fat synthesis, were influenced. This also indicates that adipose tissue lipolysis was not influenced. Interestingly, however, plasma concentrations of $\mathrm{BHB}$, the endogenous ligand of the HCAR2 receptor (Offermanns et al., 2011), were higher in the control group, which may have counteracted an effect of NA on HCAR2 and lipolysis. The similar HCAR2 expression in liver and muscle in both groups also does not contradict the view that HCAR2 receptor activity remained unchanged. To explain the observed effect on milk fat yield in the present study, it may be speculated that NA could have affected uptake into or metabolism of lipids in the mammary gland.

To study the muscle phenotype, we considered 3 muscles of the hindlimb (SM, ST) and back (LD), which are classified as fast-twitch muscles with a high percentage of type II fibers (Schiaffino and Reggiani, 2011). These muscles were expected to have a high potential for fiber switching toward a higher proportion of oxidative fibers. However, we found, in disagreement with our hypothesis, that NA supplementation did not affect the proportions of type I or type II fibers, or the ratio of type II:type I fibers. The finding of an unchanged ratio of type II:type I fibers was confirmed by largely unchanged transcript levels of $\mathrm{MYH}^{\mathrm{r}}$, which encodes the myosin heavy chains of type I fibers in the muscle motor units (Schiaffino and Reggiani, 2011). It is noteworthy that, within the class of type II fibers, NA treatment induced a moderate shift toward an increase of type IIa fibers at the expense of type IIx fibers, in LD muscle $(P<0.10)$ and ST muscle $(P<$ 0.05). Although both IIx and IIa fibers are abundant in fast-twitch muscles with high levels of glycolytic enzymes, IIa fibers are also equipped with a higher activity of oxidative enzymes (Schiaffino and Reggiani, 2011). In LD muscle, these changes were confirmed by lower transcript levels of $M Y H 1$ (encoding type IIx fibers; $P<0.05$ ) and higher transcript levels of $V E G F A$ and $\operatorname{VEGFB}(P<0.10)$ that encode the angiogenic factors VEGFA and VEGFB. It is known that muscle fiber type transformation is accompanied or preceded by angiogenesis, resulting in increased capillary density (Waters et al., 2004). The increased ratios of type IIa: type IIx fibers in LD and ST muscles thus indicate that the oxidative capacity of these muscles could have been slightly enhanced in the NA group compared with the control group. However, gene expression analyses in the muscles showed that relative mRNA concentrations of genes involved in fatty acid uptake and oxidative utilization of fatty acids via $\beta$-oxidation, tricarboxylic acid

Table 4. Relative mRNA levels of genes involved in fiber type transformation and angiogenesis in the longissimus lumborum, semitendinosus, and semimembranosus of dairy cows fed either a control diet (control) or a diet supplemented with rumen-protected niacin (niacin) ${ }^{1}$

\begin{tabular}{|c|c|c|c|c|c|c|c|}
\hline Item & \multicolumn{2}{|c|}{1 wk postpartum } & \multicolumn{2}{|c|}{3 wk postpartum } & \multicolumn{3}{|c|}{$P$-value } \\
\hline MYH2 & $1.00 \pm 0.27$ & $1.43 \pm 0.30$ & $1.12 \pm 0.27$ & $1.79 \pm 0.43$ & 0.13 & 0.80 & 0.96 \\
\hline MYH1 & $1.00 \pm 0.09$ & $0.74 \pm 0.07$ & $1.71 \pm 0.15$ & $1.33 \pm 0.13$ & 0.004 & $<0.001$ & 0.86 \\
\hline$V E G F A$ & $1.00 \pm 0.18$ & $1.36 \pm 0.27$ & $0.98 \pm 0.20$ & $1.46 \pm 0.25$ & 0.05 & 0.69 & 0.31 \\
\hline MYH7 & $1.00 \pm 0.16$ & $1.52 \pm 0.20$ & $0.95 \pm 0.15$ & $1.44 \pm 0.21$ & $<0.001$ & 0.74 & 0.73 \\
\hline MYH2 & $1.00 \pm 0.37$ & $1.33 \pm 0.41$ & $0.95 \pm 0.27$ & $1.36 \pm 0.42$ & 0.38 & 0.87 & 0.77 \\
\hline MYH1 & $1.00 \pm 0.13$ & $1.00 \pm 0.12$ & $1.27 \pm 0.11$ & $1.17 \pm 0.16$ & 0.41 & 0.16 & 0.34 \\
\hline$V E G F A$ & $1.00 \pm 0.24$ & $1.07 \pm 0.19$ & $0.49 \pm 0.12$ & $0.66 \pm 0.16$ & 0.12 & 0.010 & 0.86 \\
\hline$V E G F B$ & $1.00 \pm 0.17$ & $0.92 \pm 0.14$ & $0.54 \pm 0.09$ & $0.83 \pm 0.19$ & 0.62 & 0.030 & 0.46 \\
\hline \multicolumn{8}{|c|}{ Semimembranosus } \\
\hline$M Y H^{7}$ & $1.00 \pm 0.14$ & $0.91 \pm 0.09$ & $0.68 \pm 0.09$ & $1.06 \pm 0.12$ & 0.14 & 0.053 & 0.001 \\
\hline
\end{tabular}

${ }^{1}$ Mean \pm SEM are displayed $(\mathrm{n}=15$ and 14 animals in the control and niacin group). 

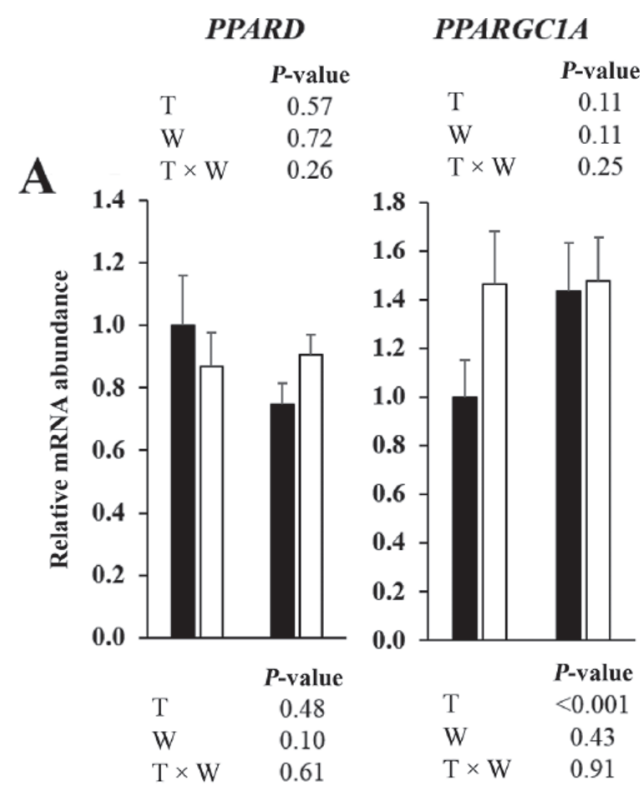

-Control

$\square$ Niacin

B
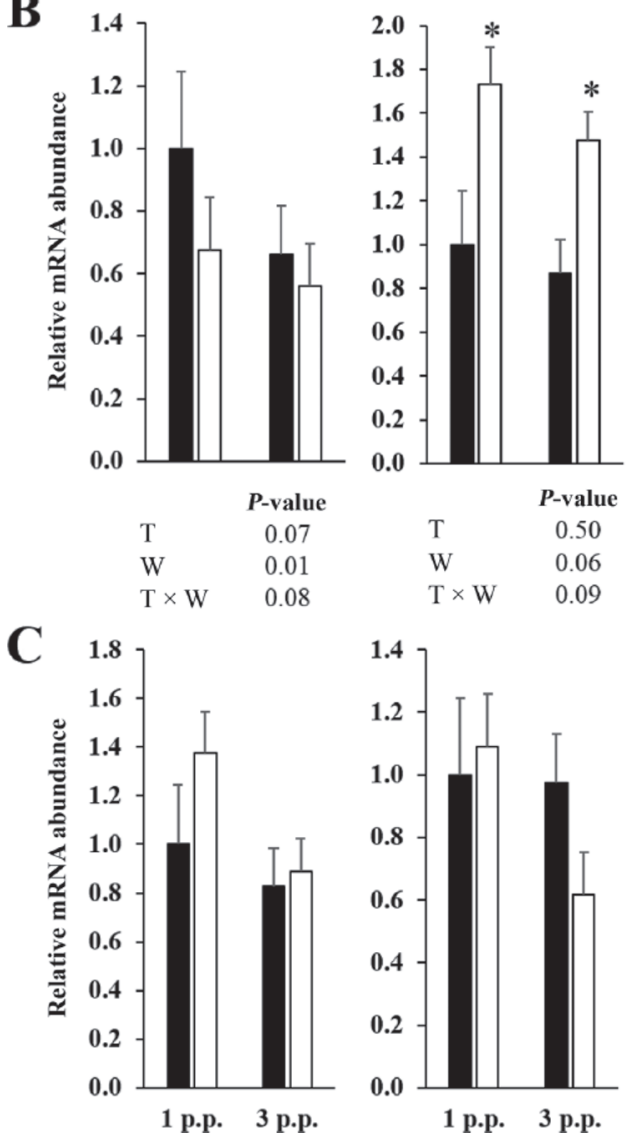

Figure 4. Relative mRNA abundance (fold of control) of peroxisome proliferator activated receptor $\delta(P P A R D)$ and PPAR- $\gamma$ coactivator1- $\alpha$ (PPARGC1A) in the longissimus lumborum (A), semitendinosus (B), and semimembranosus (C) of dairy cows fed either a control diet (control) or a diet supplemented with rumen-protected niacin (niacin; $\mathrm{n}=15$ and 14 animals in the control and niacin group; mean \pm SEM) at 1 and 3 wk postpartum (p.p.). ${ }^{*}$ Denotes a difference $(P<0.05)$ between the control and niacin group at the respective time point. $\mathrm{T}$ $=$ treatment; $\mathrm{W}=$ week; $\mathrm{T} \times \mathrm{W}=$ interaction of treatment and week. cycle, and oxidative phosphorylation were not influenced by NA treatment. Obviously, even the observed increase of the ratio of IIa:IIx fibers in ST and LD muscle induced by NA failed to cause any alteration in the metabolic phenotype of those muscles. The analyses performed in skeletal muscle overall indicate that NA treatment did not influence FA uptake and utilization in skeletal muscle.

The finding that NA treatment did not influence muscle fiber composition is in contrast to our recent studies in growing rats, pigs, and sheep. A possible reason for these diverging results between the present study and the studies performed in nonlactating animals (Khan et al., 2013a,b; Ringseis et al., 2013) may be that growing and lactating animals differ profoundly in metabolism and energy balance (Allen et al., 1994). The metabolic phenotype of skeletal muscle is mainly regulated by PPARD, the main PPAR isoform occurring in muscle, and PPARGC1A, a multifunctional coregulator. Activation of both of these transcription factors in skeletal muscle enhances the formation of type I fibers, stimulates mitochondrial biogenesis, and induces the transcription of a broad spectrum of enzymes involved in oxidative energy production (i.e., the utilization of fatty acids as oxidative fuels; Ehrenborg and Krook, 2009; Liu and Lin, 2011). In studies with the nonlactating animals, NA treatment caused a strong upregulation of both PPARD and PPARGC1A in skeletal muscles, which might provide the molecular basis for the muscle fiber transition and the induction of the oxidative muscle phenotype observed in these animals (Khan et al., 2013a,b; Ringseis et al., 2013). However, both of these transcription factors in skeletal muscle are also regulated by nutritional factors. In this respect, it has been shown that energy deprivation leads to an upregulation of both PPARD and PPARGC1A in skeletal muscles, resulting in an increased energy production from fatty acids (de Lange et al., 2006; Ehrenborg and Krook, 2009). It is likely that upregulation of these transcription by energy deprivation is caused by an increased amount of NEFA delivered from adipose tissue to skeletal muscle in the state of a NEB (Ehrenborg and Krook, 2009). Fatty acids are acting as activators of PPARD, and an increased activity of PPARD is associated with an upregulation of PPARGC1A (de Lange et al., 2006). Dairy cows in early lactation are typically in $\mathrm{NEB}$, and it is expected that increased NEFA plasma concentrations resulting from lipolysis in adipose might activate $P P A R D$ in skeletal muscle. Indeed, it has been recently shown that $P P A R D$ in skeletal is upregulated in dairy cows during the transition from pregnancy. It has been assumed that an upregulation of $P P A R D$ causes an increased transport of NEFA into muscle and subsequent oxidation, which helps to protect the liver 
Table 5. Relative mRNA levels of genes involved in the utilization of fatty acids and glucose in the semitendinosus of dairy cows fed either a control diet (control) or a diet supplemented with rumen-protected niacin (niacin) ${ }^{1}$

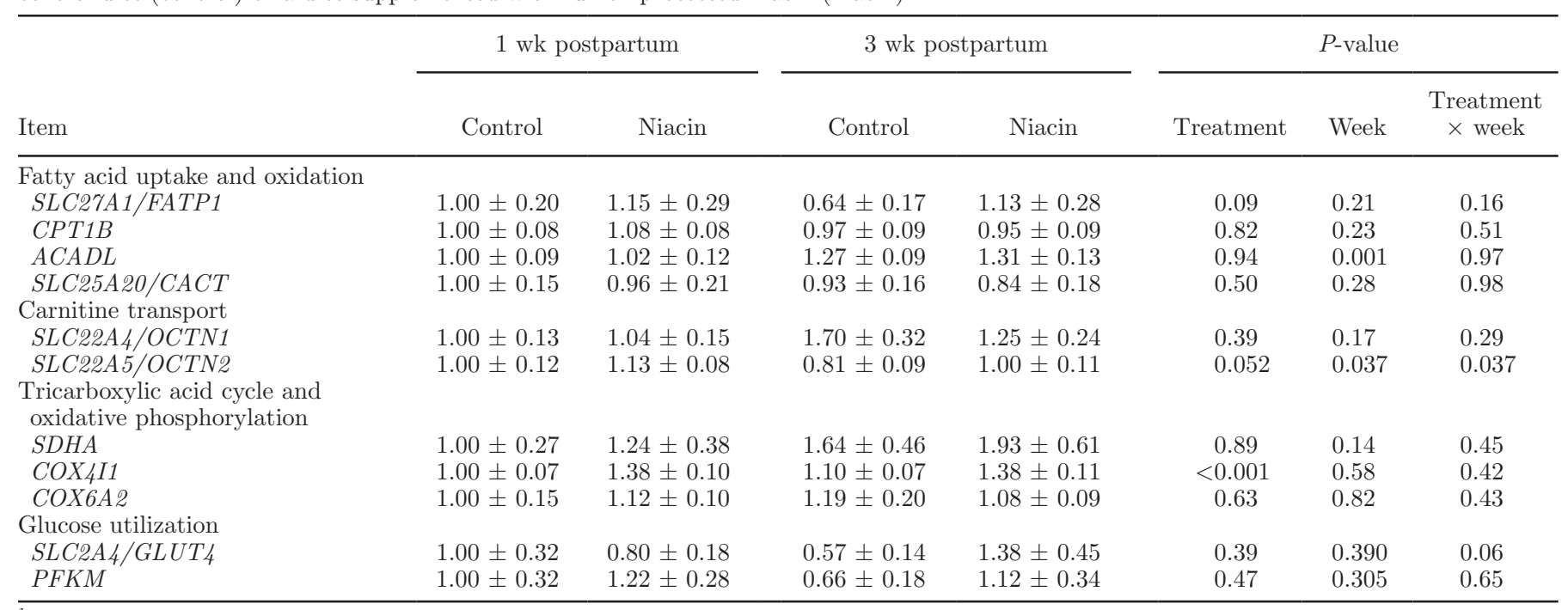

${ }^{1}$ Mean \pm SEM are displayed ( $\mathrm{n}=15$ and 14 animals in the control and niacin group).

from excess fat load during the first days after parturition (Schäff et al., 2013). This assumption, however, could provide an explanation for the lack of effect of NA treatment on muscle fiber composition and phe- notype in this study. If PPARD in skeletal muscle was already activated by high plasma NEFA concentrations occurring during early lactation it seems plausible that NA treatment did not further enhance biochemical ef-

Table 6. Relative mRNA levels in the liver of dairy cows fed either a control diet (control) or a diet supplemented with rumen-protected niacin $(\text { niacin })^{1}$

\begin{tabular}{|c|c|c|c|c|c|c|c|}
\hline \multirow[b]{2}{*}{ Item } & \multicolumn{2}{|c|}{1 wk postpartum } & \multicolumn{2}{|c|}{3 wk postpartum } & \multicolumn{3}{|c|}{$P$-value } \\
\hline & Control & Niacin & Control & Niacin & Treatment & Week & $\begin{array}{c}\text { Treatment } \\
\quad \times \text { week }\end{array}$ \\
\hline \multicolumn{8}{|c|}{ Fatty acid uptake and oxidation } \\
\hline PPARA & $1.00 \pm 0.15$ & $1.13 \pm 0.19$ & $1.08 \pm 0.13$ & $1.21 \pm 0.12$ & 0.35 & 0.08 & 0.53 \\
\hline SLC25A20/CACT & $1.00 \pm 0.09$ & $1.07 \pm 0.09$ & $0.84 \pm 0.04$ & $0.81 \pm 0.06$ & 0.92 & $<0.001$ & 0.48 \\
\hline CD36 & $1.00 \pm 0.15$ & $1.70 \pm 0.22$ & $1.44 \pm 0.20$ & $1.77 \pm 0.31$ & 0.06 & 0.28 & 0.004 \\
\hline$C P T 1 A$ & $1.00 \pm 0.19$ & $1.17 \pm 0.20$ & $1.04 \pm 0.17$ & $1.05 \pm 0.16$ & 0.63 & 0.74 & 0.40 \\
\hline$A C A D L$ & $1.00 \pm 0.10$ & $1.18 \pm 0.15$ & $0.90 \pm 0.09$ & $1.09 \pm 0.09$ & 0.18 & 0.10 & 0.34 \\
\hline$A C A D M$ & $1.00 \pm 0.11$ & $1.11 \pm 0.13$ & $0.94 \pm 0.10$ & $1.09 \pm 0.10$ & 0.32 & 0.21 & 0.33 \\
\hline SLC22A5/OCTN2 & $1.00 \pm 0.15$ & $1.08 \pm 0.13$ & $1.28 \pm 0.21$ & $1.08 \pm 0.16$ & 0.93 & 0.72 & 0.40 \\
\hline \multicolumn{8}{|l|}{ Lipogenesis } \\
\hline SREBF1 & $1.00 \pm 0.15$ & $1.16 \pm 0.18$ & $1.20 \pm 0.20$ & $1.62 \pm 0.32$ & 0.23 & 0.06 & 0.66 \\
\hline$A C A C A$ & $1.00 \pm 0.18$ & $1.23 \pm 0.22$ & $0.90 \pm 0.15$ & $2.15 \pm 0.58$ & 0.03 & 0.72 & 0.18 \\
\hline$F A S N$ & $1.00 \pm 0.20$ & $1.38 \pm 0.31$ & $0.81 \pm 0.12$ & $1.70 \pm 0.39$ & 0.09 & 0.90 & 0.53 \\
\hline$G P A M$ & $1.00 \pm 0.21$ & $1.36 \pm 0.25$ & $0.94 \pm 0.14$ & $1.31 \pm 0.25$ & 0.13 & 0.41 & 0.81 \\
\hline$D G A T 2$ & $1.00 \pm 0.08$ & $0.94 \pm 0.06$ & $0.84 \pm 0.05$ & $0.85 \pm 0.08$ & 0.75 & 0.067 & 0.88 \\
\hline \multicolumn{8}{|l|}{ Ketogenesis } \\
\hline$A C A T 1$ & $1.00 \pm 0.06$ & $0.93 \pm 0.04$ & $0.94 \pm 0.06$ & $0.87 \pm 0.06$ & 0.27 & 0.13 & 0.88 \\
\hline$F G F 21$ & $1.00 \pm 0.34$ & $0.26 \pm 0.06$ & $0.44 \pm 0.06$ & $0.19 \pm 0.06$ & $<0.001$ & 0.08 & 0.94 \\
\hline$H M G C S 2$ & $1.00 \pm 0.07$ & $1.17 \pm 0.12$ & $1.00 \pm 0.07$ & $1.02 \pm 0.09$ & 0.50 & 0.26 & 0.42 \\
\hline \multicolumn{8}{|c|}{ Unfolded protein response } \\
\hline$A T F 4$ & $1.00 \pm 0.13$ & $1.18 \pm 0.12$ & $0.89 \pm 0.12$ & $0.93 \pm 0.08$ & 0.34 & 0.017 & 0.77 \\
\hline$X B P 1$ & $1.00 \pm 0.19$ & $0.96 \pm 0.15$ & $0.80 \pm 0.10$ & $0.88 \pm 0.11$ & 0.60 & 0.30 & 0.70 \\
\hline EDEM1 & $1.00 \pm 0.13$ & $1.32 \pm 0.10$ & $1.15 \pm 0.12$ & $1.22 \pm 0.11$ & 0.05 & 0.83 & 0.19 \\
\hline$D N J A C 3$ & $1.00 \pm 0.22$ & $1.19 \pm 0.21$ & $1.19 \pm 0.18$ & $1.20 \pm 0.21$ & 0.40 & 0.94 & 0.15 \\
\hline HSPA5 & $1.00 \pm 0.26$ & $1.14 \pm 0.15$ & $1.02 \pm 0.19$ & $0.97 \pm 0.17$ & 0.43 & 0.28 & 0.33 \\
\hline HERPUD1 & $1.00 \pm 0.14$ & $0.92 \pm 0.08$ & $0.87 \pm 0.12$ & $0.90 \pm 0.10$ & 0.77 & 0.32 & 0.60 \\
\hline
\end{tabular}

${ }^{1}$ Mean \pm SEM are displayed ( $\mathrm{n}=15$ and 14 animals in the control and niacin group). 
fects triggered by PPARD, and by PPARGC1A, which is closely related to PPARD.

One hypothesis underlying this study was that an increased uptake of NEFA into skeletal muscle by NA treatment could reduce the amounts of NEFA delivered to the liver. However, as FA uptake into skeletal muscle, according the results of gene expression analysis, obviously was not enhanced, the amount of NEFA delivered to the liver was probably also unchanged. This suggestion agrees with the observation that expression of hepatic genes in fatty acid utilization, lipogenesis, and ketogenesis as well as hepatic TG concentration were not affected by the NA treatment. The NEFA taken up into the liver are activators of PPARD, the key regulator of the transcription of genes involved in fatty acid uptake, $\beta$-oxidation of fatty acids, carnitine homeostasis, and ketogenesis (Kersten et al., 1999). Therefore, a reduced uptake of NEFA into the liver would be expected to lower the expression of genes involved in these pathways. The finding that hepatic TG concentration, which is another parameter that is closely related to NEFA uptake into the liver (Grum et al., 1996; Hocquette and Bauchart, 1999), was also not different between control cows and cows supplemented with NA, is another indication that NEFA uptake into the liver was not influenced by NA treatment. The finding that NA treatment did not influence genes of fatty acid oxidation agrees with a previous study of Grum et al. (2002), which showed that supplemental NA does not influence palmitate oxidation in liver homogenates of dairy cows in early lactation. Moreover, the finding that hepatic TG concentration was not influenced by NA treatment agrees with previous studies, which also did not observe an effect of rumen-protected NA on hepatic TG concentration in early-lactating dairy cows (Morey et al., 2011; Yuan et al., 2012). The finding that liver carnitine concentration as well as the expression of hepatic SLC22A5/OCTN2, the most important carnitine transporter, was not influenced by NA treatment fits into this picture. Carnitine homeostasis (carnitine synthesis, carnitine uptake into cells) is regulated by PPARA (Ringseis and Eder, 2009), and it has been shown that conditions leading to an activation of PPARA by an increased flow of NEFA into the liver, including fasting or energy restriction, are inducing an upregulation of carnitine synthesis and carnitine uptake in the liver, associated with an increase of carnitine concentration in the liver (Luci et al., 2008; Ringseis et al., 2009; Schlegel et al., 2012b). Hence, the finding that liver carnitine concentration remained unchanged is another indication that NA did not influence the flow of NEFA into the liver.
In the present study, the observed reduction of plasma BHB in wk 2 and 3 in the cows treated with NA in comparison to control cows was surprising for several reasons. First, this finding is in contrast to almost all studies dealing with NA supplementation in dairy cows which did not find an effect of rumen-protected (Yuan et al., 2012) or non-rumen-protected NA (e.g., Driver et al., 1990; Christensen et al., 1996; Drackley et al., 1998) on plasma BHB concentration in dairy cows during early lactation. However, in some cases, a reduction in plasma BHB concentrations due to NA treatment has been reported as well (Fronk and Schultz, 1979; Erickson et al., 1992; Morey et al., 2011). Second, plasma concentrations of NEFA, the key metabolite for the production of ketone bodies in the liver, were not different between control cows and cows supplemented with NA. Third, expression of HMGCS2, the key enzyme of ketogenesis in the liver (Hegardt, 1999), was unchanged in the cows treated with NA. However, we observed that expression of FGF21 in the liver was decreased in cows treated with NA. The FGF21 has been identified as a novel stress hormone that is induced by a variety of environmental and metabolic stressors (Kim and Lee, 2015). Recent findings suggest that FGF21 plays an adaptive role in maintaining energy homeostasis during stressful conditions (Kim and Lee, 2014). Besides other metabolic changes induced by FGF21 such as an increase of lipolysis, glucose uptake, or fatty acid oxidation, FGF21 is regarded as a key regulator of ketogenesis (Badman et al., 2007). Interestingly, FGF21 is strongly induced in the liver in dairy cows during the transition from pregnancy to lactation (Carriquiry et al., 2009; Schoenberg et al., 2011; Schlegel et al., 2013). It has been suggested that the induction of FGF21 in the liver of dairy cows is due to metabolic stress occurring in the peripartum phase, which aims to maintain energy homeostasis during this phase (Schoenberg et al., 2011; Kim and Lee, 2015). For example, it has been shown that energy deficits caused by fasting induce hepatic FGF21 expression via PPARA (Badman et al., 2007) and that protein and AA restriction increase hepatic FGF21 expression as well (Kim and Lee, 2015). However, neither energy deficit nor PPARA expression differed between groups in the present study. Moreover, it has been found that FGF21 is particularly induced by ER stress (Schaap et al., 2013), a condition that has been observed in the liver of cows during early lactation (Gessner et al., 2014). To find out whether NA treatment could have attenuated ER stress in the liver of the cows, we determined mRNA concentrations of several genes of the UPR, which is triggered by the occurrence of ER stress. The finding that the expression of these 
genes in the liver remained unchanged indicates that NA treatment did not influence the occurrence of ER stress in the liver in wk 1 and 3 . Thus, it is possible that NA treatment improved stress conditions, other than ER stress, which in turn led to a reduced expression of FGF21 in the liver. For example, NA has been reported to strengthen the intestinal barrier and reduce passage of bacterial endotoxins (Zhong et al., 2015), which are increased under rumen acidosis conditions that frequently occur in high-yielding transition cows (Gozho et al., 2007). The reduced expression of FGF21 in the liver could be involved in the reduced plasma BHB concentrations observed in cows treated with NA in wk 2 and 3 p.p. However, further research is required to establish a potential interaction between NA treatment, FGF21, and ketogenesis in dairy cows. The disagreement of our study with many other studies dealing with the effects of NA treatment on ketogenesis in dairy cows could be due to the fact that the NA dosage used in our study was 2 to 10 times higher and plasma NAM concentrations were 2 to 4 times higher than in most other studies (e.g., Niehoff et al., 2009; Morey et al., 2011; Yuan et al., 2012), suggesting that effects of NA on ketogenesis are possibly occurring only at very high plasma levels. In addition, it has to be noted that plasma BHB concentrations were below the threshold for subclinical ketosis in both groups.

\section{CONCLUSIONS}

Data of the present study show that high dosages of rumen-protected NA do not influence muscle fiber composition and the metabolic phenotype of skeletal muscle in dairy cows during early lactation. This finding indicates that NA treatment does not increase fatty acid utilization in skeletal muscle of cows. Gene expression analyses, moreover, indicate that NA treatment does not alter lipid metabolism (fatty acid oxidation, lipogenesis) in the liver during early lactation. Moreover, we observed that plasma concentration of $\mathrm{BHB}$ was reduced by NA treatment during early lactation, an effect that could be due to a reduced expression of FGF21, a regulator of ketogenesis, observed in the liver of cows supplemented with NA.

\section{ACKNOWLEDGMENTS}

This study was supported by a grant from the German Research Foundation (DFG, Bonn), project no. ED 70/13-1. We gratefully thank the staff of the Educational and Research Centre for Animal Husbandry, Hofgut Neumuehle, and the technical staff of the University Giessen.

\section{REFERENCES}

Allen, L. H., J. King, and B. Lonnerdal. 1994. Nutrient regulation during pregnancy, lactation, and infant growth, 1st ed. Springer, New York, NY.

AOAC International. 2006. Official Methods of Analysis. 17th ed. AOAC International, Gaithersburg, MD.

Badman, M. K., P. Pissios, A. R. Kennedy, G. Koukos, J. S. Flier, and E. Maratos-Flier. 2007. Hepatic fibroblast growth factor 21 is regulated by PPARalpha and is a key mediator of hepatic lipid metabolism in ketotic states. Cell Metab. 5:426-437.

Barter, P. J., and K.-A. Rye. 2016. New era of lipid-lowering drugs. Pharmacol. Rev. 68:458-475.

Bloemberg, D., and J. Quadrilatero. 2012. Rapid determination of myosin heavy chain expression in rat, mouse, and human skeletal muscle using multicolor immunofluorescence analysis. PLoS One 7:e35273. https://doi.org/10.1371/journal.pone.0035273.

Bobe, G., J. W. Young, and D. C. Beitz. 2004. Invited review: Pathology, etiology, prevention, and treatment of fatty liver in dairy cows. J. Dairy Sci. 87:3105-3124.

Carriquiry, M., W. J. Weber, S. C. Fahrenkrug, and B. A. Crooker. 2009. Hepatic gene expression in multiparous Holstein cows treated with bovine somatotropin and fed n-3 fatty acids in early lactation. J. Dairy Sci. 92:4889-4900.

Choi, S., H. Yoon, K.-S. Oh, Y. T. Oh, Y. I. Kim, I. Kang, and J. H. Youn. 2011. Widespread effects of nicotinic acid on gene expression in insulin-sensitive tissues: Implications for unwanted effects of nicotinic acid treatment. Metabolism 60:134-144.

Christensen, R. A., T. R. Overton, J. H. Clark, J. K. Drackley, D. R. Nelson, and S. A. Blum. 1996. Effects of dietary fat with or without nicotinic acid on nutrient flow to the duodenum of dairy cows. J. Dairy Sci. 79:1410-1424.

de Lange, P., P. Farina, M. Moreno, M. Ragni, A. Lombardi, E. Silvestri, L. Burrone, A. Lanni, and F. Goglia. 2006. Sequential changes in the signal transduction responses of skeletal muscle following food deprivation. FASEB J. 20:2579-2581.

Drackley, J. K., D. W. LaCount, J. P. Elliott, T. H. Klusmeyer, T. R. Overton, J. H. Clark, and S. A. Blum. 1998. Supplemental fat and nicotinic acid for Holstein cows during an entire lactation. J. Dairy Sci. 81:201-214.

Driver, L. S., R. R. Grummer, and L. H. Schultz. 1990. Effects of feeding heat-treated soybeans and niacin to high producing cows in early lactation. J. Dairy Sci. 73:463-469.

Duris, M.-P., B. Picard, and Y. Geay. 2000. Specificity of different anti-myosin heavy chain antibodies in bovine muscle. Meat Sci. $55: 67-78$.

Edmonson, A. J., I. J. Lean, L. D. Weaver, T. Farver, and G. Webster 1989. A body condition scoring chart for Holstein dairy cows. J. Dairy Sci. 72:68-78.

Ehrenborg, E., and A. Krook. 2009. Regulation of skeletal muscle physiology and metabolism by peroxisome proliferator-activated receptor delta. Pharmacol. Rev. 61:373-393.

Erickson, P. S., M. R. Murphy, and J. H. Clark. 1992. Supplementation of dairy cow diets with calcium salts of long-chain fatty acids and nicotinic acid in early lactation. J. Dairy Sci. 75:1078-1089.

Feingold, K., and C. Grunfeld. 2017. Triglyceride lowering drugs. Endotext. Accessed Apr. 4, 2017. https://www.ncbi.nlm.nih.gov/ books/NBK278943/.

Fronk, T. J., and L. H. Schultz. 1979. Oral nicotinic acid as a treatment for ketosis. J. Dairy Sci. 62:1804-1807.

Gessner, D. K., G. Schlegel, R. Ringseis, F. J. Schwarz, and K. Eder. 2014. Up-regulation of endoplasmic reticulum stress induced genes of the unfolded protein response in the liver of periparturient dairy cows. BMC Vet. Res. 10:46-54.

GfE (German Society of Nutrition Physiology). 2001. Recommendations for energy and nutrient requirements for dairy cows and heifers. DLG-Verlag, Frankfurt a. Main, Germany [in German].

Gozho, G. N., D. O. Krause, and J. C. Plaizier. 2007. Ruminal lipopolysaccharide concentration and inflammatory response during grain-induced subacute ruminal acidosis in dairy cows. J. Dairy Sci. 90:856-866 
Grum, D. E., J. K. Drackley, and J. H. Clark. 2002. Fatty acid metabolism in liver of dairy cows fed supplemental fat and nicotinic acid during an entire lactation. J. Dairy Sci. 85:3026-3034.

Grum, D. E., J. K. Drackley, R. S. Younker, D. W. LaCount, and J. J. Veenhuizen. 1996. Nutrition during the dry period and hepatic lipid metabolism of periparturient dairy cows. J. Dairy Sci. 79:1850-1864.

Hegardt, F. G. 1999. Mitochondrial 3-hydroxy-3-methylglutaryl-CoA synthase: A control enzyme in ketogenesis. Biochem. J. 338:569582 .

Hirche, F., M. Fischer, J. Keller, and K. Eder. 2009. Determination of carnitine, its short chain acyl esters and metabolic precursors trimethyllysine and $\gamma$-butyrobetaine by quasi-solid phase extraction and MS/MS detection. J. Chromatogr. B Analyt. Technol. Biomed. Life Sci. 877:2158-2162.

Hocquette, J.-F., and D. Bauchart. 1999. Intestinal absorption, blood transport and hepatic and muscle metabolism of fatty acids in preruminant and ruminant animals. Reprod. Nutr. Dev. 39:27-48.

Inamadugu, J. K., R. Damaramadugu, R. Mullangi, and V. Ponneri. 2010. Simultaneous determination of niacin and its metabolitesnicotinamide, nicotinuric acid and N-methyl-2-pyridone-5-carboxamide - in human plasma by LC-MS/MS and its application to a human pharmacokinetic study. Biomed. Chromatogr. 24:10591074.

Kersten, S., J. Seydoux, J. M. Peters, F. J. Gonzalez, B. Desvergne, and W. Wahli. 1999. Peroxisome proliferator-activated receptor alpha mediates the adaptive response to fasting. J. Clin. Invest. 103:1489-1498.

Khan, M., A. Couturier, J. F. Kubens, E. Most, F.-C. Mooren, K. Krüger, R. Ringseis, and K. Eder. 2013a. Niacin supplementation induces type II to type I muscle fiber transition in skeletal muscle of sheep. Acta Vet. Scand. 55:85-94.

Khan, M., R. Ringseis, F.-C. Mooren, K. Krüger, E. Most, and K. Eder. 2013b. Niacin supplementation increases the number of oxidative type I fibers in skeletal muscle of growing pigs. BMC Vet. Res. 9:177-184.

Kim, K. H., and M. S. Lee. 2014. FGF21 as a stress hormone: The roles of FGF21 in stress adaptation and the treatment of metabolic diseases. Diabetes Metab. J. 38:245-251.

Kim, K. H., and M. S. Lee. 2015. FGF21 as a mediator of adaptive responses to stress and metabolic benefits of anti-diabetic drugs. J. Endocrinol. 226:R1-R16.

Liu, C., and J. D. Lin. 2011. PGC-1 coactivators in the control of energy metabolism. Acta Biochim. Biophys. Sin. (Shanghai) 43:248257.

Liu, M., D. Zhang, X. Wang, L. Zhang, J. Han, M. Yang, X. Xiao, Y. Zhang, and H. Liu. 2012. Simultaneous quantification of niacin and its three main metabolites in human plasma by LC-MS/MS J. Chromatogr. B Analyt. Technol. Biomed. Life Sci. 904:107-114.

Livak, K. J., and T. D. Schmittgen. 2001. Analysis of relative gene expression data using real-time quantitative PCR and the 2(-Delta Delta C(T)) method. Methods 25:402-408.

Luci, S., F. Hirche, and K. Eder. 2008. Fasting and caloric restriction increases mRNA concentrations of novel organic cation transporter-2 and carnitine concentrations in rat tissues. Ann. Nutr. Metab. 52:58-67.

Metwally, A., M. Deml, C. Fahn, and W. Windisch. 2015. Effects of a specific blend of essential oil on rumen degradability, total tract digestibility and fermentation characteristics in rumen fistulated cows. Glob. Vet. 15:441-451.

Morey, S. D., L. K. Mamedova, D. E. Anderson, C. K. Armendariz, E. C. Titgemeyer, and B. J. Bradford. 2011. Effects of encapsulated niacin on metabolism and production of periparturient dairy cows. J. Dairy Sci. 94:5090-5104.

Niehoff, I.-D., L. Hüther, and P. Lebzien. 2009. Niacin for dairy cattle: A review. Br. J. Nutr. 101:5-19.

Offermanns, S. 2006. The nicotinic acid receptor GPR109A (HM74A or PUMA-G) as a new therapeutic target. Trends Pharmacol. Sci. $27: 384-390$.

Offermanns, S., S. L. Colletti, T. W. Lovenberg, G. Semple, A. Wise, and A. P. IJzerman. 2011. International Union of Basic and
Clinical Pharmacology. LXXXII: Nomenclature and classification of hydroxy-carboxylic acid receptors (GPR81, GPR109A, and GPR109B). Pharmacol. Rev. 63:269-290.

Ørskov, E. R., and I. McDonald. 1979. The estimation of protein degradability in the rumen from incubation measurements weighted according to rate of passage. J. Agric. Sci. 92:499-503.

Pires, J. A. A., and R. R. Grummer. 2007. The use of nicotinic acid to induce sustained low plasma nonesterified fatty acids in feedrestricted Holstein cows. J. Dairy Sci. 90:3725-3732.

Ringseis, R., and K. Eder. 2009. Influence of pharmacological PPARalpha activators on carnitine homeostasis in proliferating and non-proliferating species. Pharmacol. Res. 60:179-184.

Ringseis, R., N. Wege, G. Wen, C. Rauer, F. Hirche, H. Kluge, and K. Eder. 2009. Carnitine synthesis and uptake into cells are stimulated by fasting in pigs as a model of nonproliferating species. J. Nutr. Biochem. 20:840-847.

Ringseis, R., S. Rosenbaum, D. K. Gessner, L. Herges, J. F. Kubens, F.-C. Mooren, K. Krüger, and K. Eder. 2013. Supplementing obese Zucker rats with niacin induces the transition of glycolytic to oxidative skeletal muscle fibers. J. Nutr. 143:125-131.

Schaap, F. G., A. E. Kremer, W. H. Lamers, P. L. Jansen, and I. C. Gaemers. 2013. Fibroblast growth factor 21 is induced by endoplasmic reticulum stress. Biochimie 95:692-699.

Schäff, C., S. Börner, S. Hacke, U. Kautzsch, H. Sauerwein, S. K. Spachmann, M. Schweigel-Röntgen, H. M. Hammon, and B. Kuhla. 2013. Increased muscle fatty acid oxidation in dairy cows with intensive body fat mobilization during early lactation. J. Dairy Sci. 96:6449-6460.

Schiaffino, S., and C. Reggiani. 2011. Fiber types in mammalian skeletal muscles. Physiol. Rev. 91:1447-1531.

Schindelin, J., I. Arganda-Carreras, E. Frise, V. Kaynig, M. Longair, T. Pietzsch, S. Preibisch, C. Rueden, S. Saalfeld, B. Schmid, J. Y. Tinevez, D. J. White, V. Hartenstein, K. Eliceiri, P. Tomancak, and A. Cardona. 2012. Fiji: An open-source platform for biological-image analysis. Nat. Methods 9:676-682.

Schlegel, G., J. Keller, F. Hirche, S. Geissler, F. J. Schwarz, R. Ringseis, G. I. Stangl, and K. Eder. 2012b. Expression of genes involved in hepatic carnitine synthesis and uptake in dairy cows in the transition period and at different stages of lactation. BMC Vet. Res. 8:28-39.

Schlegel, G., R. Ringseis, J. Keller, F. J. Schwarz, W. Windisch, and K. Eder. 2013. Expression of fibroblast growth factor 21 in the liver of dairy cows in the transition period and during lactation. J. Anim. Physiol. Anim. Nutr. (Berl.) 97:820-829.

Schlegel, G. R. Ringseis, W. Windisch, F. J. Schwarz, and K. Eder. 2012a. Effects of a rumen-protected mixture of conjugated linoleic acids on hepatic expression of genes involved in lipid metabolism in dairy cows. J. Dairy Sci. 95:3905-3918.

Schoenberg, K. M., S. L. Giesy, K. J. Harvatine, M. R. Waldron, C. Cheng, A. Kharitonenkov, and Y. R. Boisclair. 2011. Plasma FGF21 is elevated by the intense lipid mobilization of lactation. Endocrinology 152:4652-4661

Scholz, K., A.M. Kynast, A. Couturier, F.-C. Mooren, K. Krueger, E. Most, K. Eder, and R. Ringseis. 2014. Supplementing healthy rats with a high-niacin dose has no effect on muscle fiber distribution and muscle metabolic phenotype. Eur. J. Nutr. 53:1229-1236.

Schuler, M., F. Ali, C. Chambon, D. Duteil, J.-M. Bornert, A. Tardivel, B. Desvergne, W. Wahli, P. Chambon, and D. Metzger. 2006. PGC1 alpha expression is controlled in skeletal muscles by PPAR beta, whose ablation results in fiber-type switching, obesity, and type 2 diabetes. Cell Metab. 4:407-414.

Schwab, E. C., D. Z. Caraviello, and R. D. Shaver. 2005. Review: A meta-analysis of lactation responses to supplemental dietary niacin in dairy cows. Prof. Anim. Sci. 21:239-247.

Tienken, R., S. Kersten, L. Hüther, J. Frahm, U. Meyer, and S. Dänicke. 2015. Relative bioavailability of niacin supplements for dairy cows: Effects of rumen protection and of feed processing. Vet. Sci. $2: 440-455$.

Toniolo, L., L. Maccatrozzo, M. Patruno, F. Caliaro, F. Mascarello, and C. Reggiani. 2005. Expression of eight distinct MHC isoforms 
in bovine striated muscles: Evidence for $\mathrm{MHC}-2 \mathrm{~B}$ presence only in extraocular muscles. J. Exp. Biol. 208:4243-4253.

Vandesompele J., K. de Preter, F. Pattyn, B. Poppe, N. van Roy, A. de Paepe, and F. Speleman. 2002. Accurate normalization of real-time quantitative RT-PCR data by geometric averaging of multiple internal control genes. Genome Biol. 3:RESEARCH0034.

Wang, W., A. Basinger, R. A. Neese, B. Shane, S. A. Myong, M. Christiansen, and M. K. Hellerstein. 2001. Effect of nicotinic acid administration on hepatic very low density lipoprotein-triglyceride production. Am. J. Physiol. Endocrinol. Metab. 280:E540-E547.

Wang, Y. X., C. L. Zhang, R. T. Yu, H. K. Cho, M. C. Nelson, C. R. Bayuga-Ocampo, J. Ham, H. Kang, and R. M. Evans. 2004. Regulation of muscle fiber type and running endurance by PPAR delta. PLoS Biol. 2:1532-1539.

Waters, R. E., S. Rotevatn, P. Li, B. H. Annex, and Z. Yan. 2004. Voluntary running induces fiber type-specific angiogenesis in mouse skeletal muscle. Am. J. Physiol. Cell Physiol. 287:C1342-C1348.

White, H. M. 2015. The role of TCA cycle anaplerosis in ketosis and fatty liver in periparturient dairy cows. Animals (Basel) 5:793-802.
Wildman, E. E., G. M. Jones, P. E. Wagner, R. L. Boman, H. F. Troutt, and T. N. Lesch. 1982. A dairy cow body condition scoring system and its relationship to selected production characteristics. J. Dairy Sci. 65:495-501.

Wise, A. 2003. Molecular identification of high and low affinity receptors for nicotinic acid. J. Biol. Chem. 278:9869-9874.

Yuan, K., R. D. Shaver, S. J. Bertics, M. Espineira, and R. R. Grummer. 2012. Effect of rumen-protected niacin on lipid metabolism, oxidative stress, and performance of transition dairy cows. J. Dairy Sci. 95:2673-2679.

Zeitz, J. O., E. Most, and K. Eder. 2016. Conjugated linoleic acid influences the metabolism of tocopherol in lactating rats but has little effect on tissue tocopherol concentrations in pups. Lipids Health Dis. 15:102-111.

Zhong, W., Q. Li, W. Zhang, Q. Sun, X. Sun, and Z. Zhou. 2015. Modulation of intestinal barrier and bacterial endotoxin production contributes to the beneficial effect of nicotinic acid on alcoholinduced endotoxemia and hepatic inflammation in rats. Biomolecules 5:2643-2658. 